\title{
Mainstreaming emergency contraception in developing countries: A toolkit for policymakers and service providers
}

Wilson Liambila

Population Council

Saumya RamaRao

Population Council

Joyce Wanderi Maina

Mary W. Gathitu

Follow this and additional works at: https://knowledgecommons.popcouncil.org/departments_sbsr-rh

Part of the Demography, Population, and Ecology Commons, Family, Life Course, and Society Commons, International Public Health Commons, and the Medicine and Health Commons How does access to this work benefit you? Let us know!

\section{Recommended Citation}

Liambila, Wilson, Saumya RamaRao, Joyce Wanderi Maina, and Mary W. Gathitu. 2013. "Mainstreaming emergency contraception in developing countries: A toolkit for policymakers and service providers." Nairobi: Population Council. 


\section{MAINSTREAMIING \\ EMIERGENCY CONIRACEPIION IN DEVEILOPING COUNTRIES}

\section{A TOOLKIT FOR POLICYMAKERS AND SERVICE PROVIDERS}

WILSON N. LIAMBILA, SAUMYA RAMARAO, JOYCE WANDERI MAINA, MARY W. GATHITU

JANUARY 2013 


\section{(2) Population Council}

The Population Council confronts critical health and development issues-from stopping the spread of HIV to improving reproductive health and ensuring that young people lead full and productive lives. Through biomedical, social science, and public health research in 50 countries, we work with our partners to deliver solutions that lead to more effective policies, programmes, and technologies that improve lives around the world. Established in 1952 and headquartered in New York, the Council is a nongovernmental, nonprofit organization governed by an international board of trustees.

Population Council

General Accident House

Ralph Bunche Road

Nairobi

Kenya

Tel: +254202713480

Fax: +254202713479

www.popcouncil.org

Suggested citation: Liambila, Wilson N., Saumya RamaRao, Joyce Wanderi Maina, and Mary W. Gathitu. 2013. Mainstreaming Emergency Contraception in Developing Countries: A Toolkit for Policymakers and Service Providers. Nairobi: Population Council.

(c) 2013 The Population Council, Inc. 


\section{TABLE OF CONTENTS}

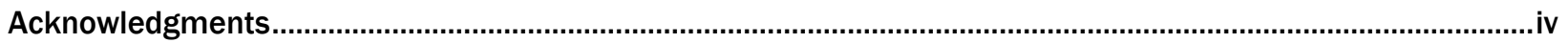

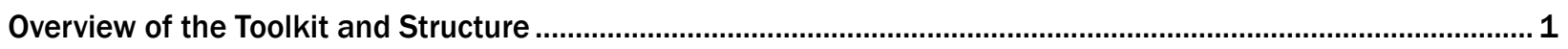

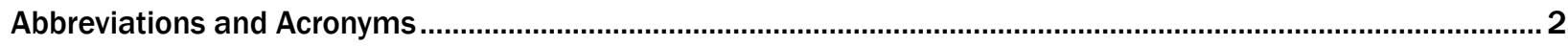

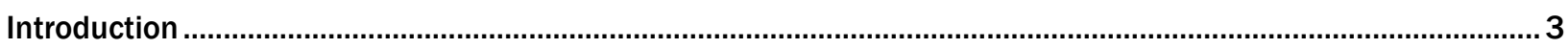

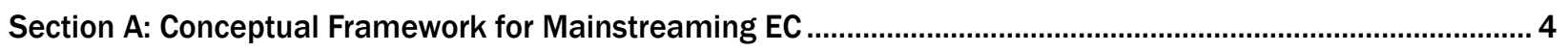

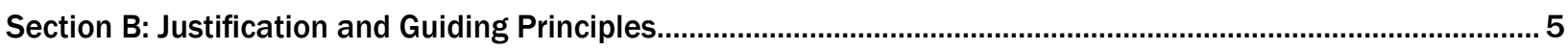

Section C: Purpose, Target Audience, and Steps Involved ............................................................................ 8

Section D: Institutional Framework and Implementation Mechanism ..............................................................10

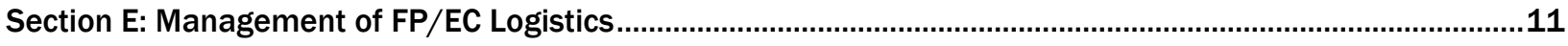

Section F: Monitoring and Evaluation Activities and Pharmacovigilance...........................................................14

Section G: Summary of Key Lessons and Programmatic Considerations..........................................................16

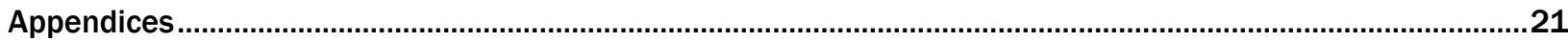

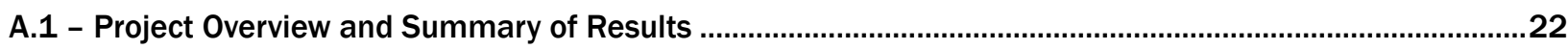

A.2 - Health Care Providers Quick Reference Guide.......................................................................................31

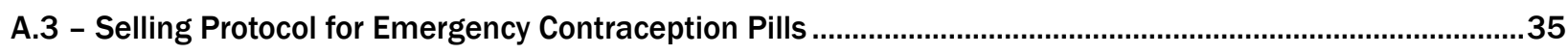

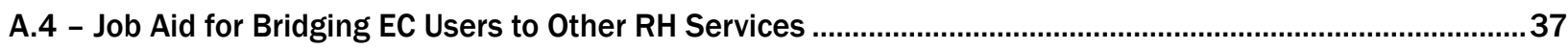

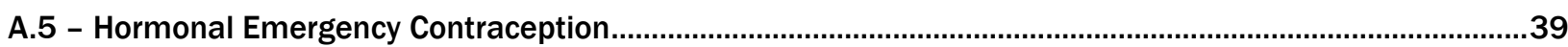

A.6 - WHO Fact Sheet on Emergency Contraception .................................................................................45

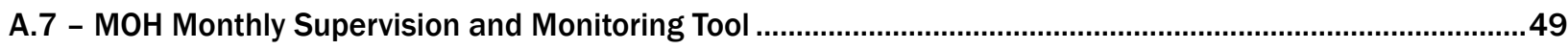

A.8 - Key M\&E Indicators for FP Commodities/EC Pills ..............................................................................53 


\section{ACKNOWLEDGMENTS}

We wish to acknowledge the individuals and a number of organizations in Kenya who have over the years made it possible to achieve the results outlined in this toolkit. In particular we wish to thank the Nursing Council of Kenya, Clinical Officers' Council, Division of Reproductive Health (DRH) in the Ministry of Public Health and Sanitation (MOPHS), Kenya Medical Supplies Agency (KEMSA), major distributors of EC brands in Kenya, Population Services International, Liverpool VCT Care and Treatment, Pharmaceutical Society of Kenya, Pharmacy and Poisons Board, and other institutions including NGOs, CBOs, partners in the USAID-supported APHIA II program, and provincial health management teams for having played different roles during the planning, implementation, and evaluation phases of the project on mainstreaming EC in Kenya.

We also wish to acknowledge the Gender Violence and Recovery Center (GVRC), Kenyatta National Hospital (KNH), Flame Tree Pharmacy, Liverpool VCT Care and Treatment, Dr. B. Monda, Lecturer in Ob/Gyn Kenyatta University and health columnist in women's reproductive health issues for having played different roles during the efforts to ensure sustained impact of the achievements of the first phase of the project on mainstreaming EC in Kenya and to the research assistants who meticulously undertook field work in many parts of Kenya.

Our colleagues in the Council (specifically, Jill Keesbury, Francis Onyango, Benta Owino, Lucy Nganga, Katherine Maina, and lan Askew) are acknowledged for having actively participated in generating the evidence that has gone into compiling the toolkit. Janet Munyasya and Teresa Atieno Bange are acknowledged for formatting the toolkit.

This initiative was made possible through the generous support of the William and Flora Hewlett Foundation, which has shown true leadership and vision in promoting EC across the world. The United Nations Population Fund (UNFPA) in Kenya also provided technical and financial assistance for work under this initiative, and has served as an active advocate for EC mainstreaming in the country. 


\section{OVERVIEW OF THE TOOLKIT AND STRUCTURE}

In late 2006, the Kenyan Ministry of Health (MOH), the Population Council, and Population Services International (PSI) launched an initiative to mainstream emergency contraception (EC) in Kenya. The initiative included a core set of activities aimed at improving overall awareness of emergency contraception across the country and strengthening the quality of EC services in both the public and private sectors. It was intended to serve as a model for other countries interested in improving access to EC, and to generate in-depth knowledge on EC program strategies and utilization characteristics in sub-Saharan Africa.

By the conclusion of the initiative, sales of EC in the private sector had more than tripled and public sector utilization also increased tremendously. Overall knowledge among providers increased significantly over the life of the initiative. Provider capacity also increased in the private sector through an innovative, noninvasive strategy to improve information provision in pharmacies. Preservice training curricula for nurses and clinical officers were updated to include $\mathrm{EC}$, and the $\mathrm{MOH}$ drew lessons and experiences from the initiative to substantially revise the EC component of the 2010 National Family Planning Guidelines for Health Providers (2010) among other achievements.

\section{Toolkit}

This toolkit on mainstreaming emergency contraception in developing countries has been developed in response to one of the objectives of the 2006 initiative that sought to generate lessons that could serve as a model for other countries interested in improving access to EC, and to generate in-depth knowledge on EC program strategies and utilization characteristics in sub-Saharan Africa. As has been pointed out in many publications, including those produced by the International Consortium on Emergency Contraception (ICEC), for many women, emergency contraceptive pills (ECPs) offer an opportunity to prevent unintended pregnancy following unprotected sex and contraceptive method failure. ECPs are also given as primary prevention of unintended pregnancy in case of rape. Hence, timely access to this safe, effective option remains an essential element of women's quality reproductive healthcare.

Yet ECPs remain inaccessible in many developing countries, especially in sub-Saharan Africa where many factors continue to undermine the ability of women to access and use ECPs. This toolkit is based on a theoretical framework that was developed from a thorough review of the available evidence from the EC mainstreaming activities implemented by the Population Council, $\mathrm{MOH}$, and PSI.

\section{Audience}

The primary target groups for the toolkit are policymakers and health care providers. It can also serve as a resource for trainers (for both pre-service and in-service students), researchers, RH program managers, and technical advisors who organize or facilitate training events and advocacy workshops for emergency contraception activities, advocates, lay community members, media, and donors. The toolkit can be used in countries where ECPs are not currently available, as well as in contexts where the intention is to expand or mainstream access to existing ECP services. The toolkit is generic and could be adapted by countries, institutions, and individual health care providers wishing to mainstream emergency contraception services in their respective settings.

\section{The structure}

The toolkit is divided into eight sections:

Section A provides the conceptual framework on mainstreaming of emergency contraception activities within the public and private sectors.

Section B addresses justification and guiding principles. 
Section $\mathrm{C}$ focuses on purpose and steps involved in mainstreaming EC.

- Section D outlines the institutional framework required to successfully mainstream EC activities.

- Section E discusses effective management of EC logistics.

- Section F addresses supervision and monitoring activities.

- Section G focuses on key programmatic considerations; and

- Section H contains appendices, which are the main products of the EC mainstreaming work.

The appendices appearing in Section $\mathrm{H}$ are as follows:

A.1 - Project Overview and Summary of Results

A.2- Health Care Providers Quick Reference Guide

A.3- Selling Protocol for Emergency Contraception Pills

A.4 - Job Aid for Bridging EC Users to Other RH Services

A.5 - Hormonal Emergency Contraception

A.6 - WHO Fact Sheet on Emergency Contraception

A.7 - MOH Monthly Supervision and Monitoring Tool

A.8 - Key M\&E Indicators for FP Commodities/EC Pills

\section{The CD-ROM includes:}

Some of the bulky reports such as the final EC mainstreaming report, the follow-up project report, and publications.

$\begin{array}{ll}\text { Abbreviations and Acronyms } \\ \text { AIDS } & \text { Acquired Immuno-Deficiency Syndrome } \\ \text { APHIA } & \text { AIDS, Population and Health Integrated } \\ & \text { Assistance } \\ \text { BCC } & \text { Behavior Change Communication } \\ \text { BSCN } & \text { Bachelor of Science in Nursing } \\ \text { CBD } & \text { Community-Based Distributor } \\ \text { CHW } & \text { Community Health Worker } \\ \text { COC } & \text { Combined Oral Contraceptive } \\ \text { CTU } & \text { Contraceptive Technology Update } \\ \text { DCMCH } & \text { Diploma in Clinical Medicine and } \\ & \text { Community Health } \\ \text { DHS } & \text { Demographic and Health Survey } \\ \text { DMPA } & \text { Depot-medroxyprogesterone acetate } \\ \text { DRH } & \text { Division of Reproductive Health } \\ \text { EC } & \text { Emergency Contraception } \\ \text { ECP } & \text { Emergency Contraceptive Pill } \\ \text { FP } & \text { Family Planning } \\ \text { GBV } & \text { Gender-Based Violence } \\ \text { HIV } & \text { Human Immuno-Deficiency Virus } \\ \text { ICEC } & \text { International Consortium for Emergency } \\ & \text { Contraception } \\ \text { IEC } & \text { Information, Education, and Communication } \\ \text { IUD } & \text { Intrauterine Contraceptive Device } \\ \text { KDHS } & \text { Kenya Demographic and Health Survey } \\ \text { KEMSA } & \text { Kenya Medical Supplies Agency } \\ \text { LMIS } & \text { Logistics Management Information System } \\ \text { M\&E } & \text { Monitoring and Evaluation } \\ \text { MCH } & \text { Maternal and Child Health } \\ \text { MIS } & \text { Management Information System } \\ \text { MOH } & \text { Ministry of Health } \\ \text { MOPHS } & \text { Ministry of Public Health and Sanitation } \\ \text { NGO } & \text { Nongovernmental Organization } \\ \text { OTC } & \text { Over-the-Counter } \\ \text { PEP } & \text { Post-Exposure Prophylaxis } \\ \text { PRC } & \text { Post-Rape Care } \\ \text { PSI } & \text { Population Services International } \\ \text { RH } & \text { Reproductive Health } \\ \text { SGBV } & \text { Sexual and Gender-Based Violence } \\ \text { SPA } & \text { Service Provision Assessment } \\ \text { STI } & \text { Sexually Transmitted Infection } \\ \text { SRH } & \text { Sexual and Reproductive Health } \\ \text { TA } & \text { Technical Assistance } \\ \text { UNFPA } & \text { United Nations Population Fund } \\ \text { VCT } & \text { Voluntary Counseling and Testing } \\ \text { World Health Organization } \\ \end{array}$

AIDS Acquired Immuno-Deficiency Syndrom

APHIA AIDS, Population and Health Integrated

BCC Behavior Change Communication

$\mathrm{BScN}$ Bachelor of Science in Nursing

CBD Community-Based Distributor

CHW Community Health Worker

COC Combined Oral Contraceptive

CTU Contraceptive Technology Update

DHS Demographic and Health Survey

DMPA Depot-medroxyprogesterone acetate

DRH Division of Reproductive Health

EC Emergency Contraception

Emergency Contraceptive Pil

HIV Human Immuno-Deficiency Virus

ICEC International Consortium for Emergency

IEC Information, Education, and Communication

IUD Intrauterine Contraceptive Device

KEMSA Kenya Medical Supplies Agency

LMIS Logistics Management Information System

M\&E Monitoring and Evaluation

$\mathrm{MCH} \quad$ Maternal and Child Health

MIS Management Information System

$\mathrm{MOH} \quad$ Ministry of Health

MOPHS Ministry of Public Health and Sanitation

NGO Nongovernmental Organization

OTC Over-the-Counter

PEP Post-Exposure Prophylaxis

PRC Post-Rape Care

PSI Population Services International

RH Reproductive Health

SGBV Sexual and Gender-Based Violence

SPA Service Provision Assessment

Sexually Transmitted Infection

Sexual and Reproductive Health

Technical Assistance

VCT Voluntary Counseling and Testing 
In late 2006, Kenya's Ministry of Health $(\mathrm{MOH})$, the Population Council, and Population Services International (PSI) launched an initiative to mainstream emergency contraception $(E C)^{*}$ in both the private and public sectors of Kenya. The specific objectives of the initiative were to: increase knowledge, awareness, and use of EC among Kenyan women aged 18-30 years; increase knowledge and awareness of EC among health care providers; and strengthen EC provision in both the private and public sectors. When the initiative concluded in 2009, sales of EC in the private sector had more than tripled, and public-sector utilization had also increased tremendously.

Overall knowledge among providers increased significantly over the life of the initiative, and those trained in EC demonstrated more favorable attitudes and practices toward EC. Provider capacity also improved in both the private and public sectors. The results of the project were disseminated to policymakers, media, donors, and program managers in June 2010. The Council was awarded a follow-up project for the period January 2010 to September 2012 to institutionalize and sustain the achievements realized under this initiative and to promote the
Kenyan experience as a model for other countries in sub-Saharan Africa. Thus, the rich experiences gained and the materials used in mainstreaming emergency contraception activities within the National Reproductive Health and Family Planning programs in Kenya, including the follow-up project, have been compiled into a toolkit for use by health care providers working in developing country contexts.

The toolkit is generic and could be adapted by countries, institutions, and individual health care providers wishing to mainstream emergency contraception activities in their respective settings. The toolkit is divided into eight sections (A, B, C, D, E, F, G, and H). Section A provides the conceptual framework on mainstreaming of emergency contraception activities within the public and private sectors. Section B addresses justification and guiding principles. Section $C$ focuses on purpose and steps involved in mainstreaming EC. Section D outlines the institutional framework required to successfully mainstream EC activities. Section E discusses effective management of EC logistics. Section $F$ addresses supervision and monitoring activities. Section $\mathrm{G}$ focuses on key programmatic considerations while Section $\mathrm{H}$ contains appendices (key products of the EC mainstreaming work).

\footnotetext{
* Emergency contraception (EC) refers to several contraceptive methods that can be used to prevent pregnancy after sex, including emergency contraceptive pills (ECPs) and intrauterine devices. They offer women an important second chance to prevent pregnancy when a regular method fails, no method was used, or sex was forced. ECPs must be taken within 120 hours of intercourse, however, the sooner they are taken, the more effective they are. Thus, the three types of ECPs are: combined ECPs containing both estrogen and progestin, progestin-only ECPs, and ECPs containing an antiprogestin (either mifepristone or ulipristal acetate).
} 


\section{SECTION A CONCEPTUAL FRAMEWORK FOR MAINSTREAMING EC}

The conceptual framework shown in Figure 1 has been constructed from the experience and evidence acquired mainly from 2006 when an initiative to mainstream emergency contraception (EC) was launched. Available frameworks (including those developed by FIGO and the World Health Organization) do not address programmatic aspects of mainstreaming emergency contraception in developing countries. Rather, they are confined to aspects such as mainstreaming emergency contraception within gender contexts or mainstreaming family planning within sexual and reproductive health (SRH) activities.
The framework shown below highlights the challenges addressed by the program over the years, project objectives, interventions carried out, and their effects or outcomes. Interventions included raising awareness through the mass media, the use of job aids, IEC materials, weekly updates on EC by retailers, development of a Quick Reference Guide, engaging leadership in EC mainstreaming, organizing for pre- and in-service training, and ensuring stock sustainability, among many other approaches shown in Figure 1.

\section{FIGURE 1 CONCEPTUAL FRAMEWORK FOR MAINSTREAMING EMERGENCY CONTRACEPTION}

ACTIVITIES AT COUNTRY LEVEL

\begin{tabular}{|c|c|c|c|}
\hline CHALLENGES & OBJECTIVES & INTERVENTIONS & EFFECTS/OUTCOMES \\
\hline $\begin{array}{l}\text { - High proportion of } \\
\text { births mistimed } \\
\text { or unwanted } \\
\text { - Use of EC can } \\
\text { reduce unwanted } \\
\text { pregnancies }\end{array}$ & $\begin{array}{l}\text { Increase } \\
\text { knowledge and } \\
\text { use of EC } \\
\text { among women } \\
\text { aged 18-30 }\end{array}$ & $\begin{array}{l}\text { Raising awareness through: } \\
\text { - Mass media campaign on radio, TV } \\
\text { - Point-of-sale materials in pharmacies } \\
\text { - Community outreach campaigns } \\
\text { - A youth hotline (One2one hotline) }\end{array}$ & $\begin{array}{l}\text { - Awareness and use of ECPs increased } \\
\text { drastically between } 2003 \text { and } 2009 \\
\text { - Media campaigns were effective in } \\
\text { disseminating key messages on EC } \\
\text { - A youth hotline increased users of EC } \\
\text { services }\end{array}$ \\
\hline $\begin{array}{l}\text { - Access to EC } \\
\text { limited (low pro- } \\
\text { portion of women } \\
\text { “ever heard" or } \\
\text { "used") } \\
\text { - Limited capacity } \\
\text { within public and } \\
\text { private sectors }\end{array}$ & $\begin{array}{l}\text { Strengthen the } \\
\text { provision of EC } \\
\text { in the private } \\
\text { sector }\end{array}$ & $\begin{array}{l}\text { Private sector interventions included } \\
\text { the use of three simple approaches: } \\
\text { - Job aids with three key messages in } \\
\text { English and local language } \\
\text { - IEC materials: brochures and posters } \\
\text { - Weekly updates on EC by retailer }\end{array}$ & $\begin{array}{l}\text { - Sales of } 4 \text { major EC brands increased } \\
\text { three times over project life } \\
\text { - Pharmacy staff improved provision of } \\
\text { basic information on ECPs to clients } \\
\text { - Pharmacy staff can effectively use job } \\
\text { aids to offer quality EC services }\end{array}$ \\
\hline $\begin{array}{l}\text { (low proportion } \\
\text { of health care } \\
\text { providers trained } \\
\text { on EC use) } \\
\text { - Pharmacists ex- } \\
\text { pressed need for } \\
\text { more information } \\
\text { on EC }\end{array}$ & $\begin{array}{l}\text { Strengthen the } \\
\text { provision of EC } \\
\text { in the public } \\
\text { sector }\end{array}$ & $\begin{array}{l}\text { Public-sector interventions included: } \\
\text { - Use of a Quick Reference Guide } \\
\text { - Engaging leadership in EC main- } \\
\text { streaming } \\
\text { - Organizing for pre- and in-service } \\
\text { training } \\
\text { - Ensuring stock sustainability } \\
\text { - Strengthening EC in national FP } \\
\text { guidelines }\end{array}$ & $\begin{array}{l}\text { - EC can now be obtained at all service } \\
\text { delivery levels } \\
\text { - Expanded list of persons to dispense } \\
\text { EC including trained CHWs/CBDs } \\
\text { - Trained providers now counsel/pro- } \\
\text { vide ECPs and have more favorable } \\
\text { attitudes }\end{array}$ \\
\hline $\begin{array}{l}\text { of health care } \\
\text { providers cor- } \\
\text { rectly identified } \\
\text { timeframe for EC } \\
\text { - Misinformation } \\
\text { and negative } \\
\text { media coverage }\end{array}$ & $\begin{array}{l}\text { Promote } \\
\text { lessons } \\
\text { learned/ } \\
\text { experience } \\
\text { as a model } \\
\text { for improving } \\
\text { access to EC in } \\
\text { the region }\end{array}$ & $\begin{array}{l}\text { Sustainability interventions included: } \\
\text { - Institutionalizing the EC initiative } \\
\text { - Providing support to the private } \\
\text { sector } \\
\text { - Leveraging additional support for EC } \\
\text { - Using evidence as a model for region }\end{array}$ & $\begin{array}{l}\text { - The EC selling/dispensing protocol ap- } \\
\text { proved by local pharmaceutical society } \\
\text { - An ongoing South-to-South collabora- } \\
\text { tion } \\
\text { - Previous experience/evidence served } \\
\text { as a basis or model for other coun- } \\
\text { tries' plans }\end{array}$ \\
\hline
\end{tabular}




\section{SECTION B JUSTIFICATION AND GUIDING}

PRINCIPLES

\section{Justification}

Emergency contraception, sometimes referred to as "morning after" or post-coital contraception provides a second chance for women who experience contraceptive failure or do not use a method, as well as for women who experience unplanned intercourse, including coerced sex or rape. Knowledge of emergency contraception is crucial, since women must know they can prevent pregnancy after intercourse in order to seek care. While rates of unwanted pregnancy vary in different countries and among population groups, the need for emergency contraception is critical especially in developing countries. Examples of contraceptive failure or incorrect use are shown in Box 1.

Despite the demonstrated safety and efficacy of emergency contraception, its acceptance by providers and the public, and its inclusion on the WHO's essential drug list, emergency contraception is not widely available in many developing countries. ${ }^{1}$ Contrary to the perceived benefits of EC, in a recent article Durrance ${ }^{2}$ concludes that increased access to EC in Washington State had no impact on abortion rates and resulted in higher STI rates (specifically gonorrhea). Similar findings have, in the past, been challenged by other researchers. For instance, in response to an earlier article published in the
Journal of Health Economics the authors criticized what they termed a "dubious association" between OTC access to EC and STI rates in the UK. ${ }^{3}$ The authors argued that the pharmacy access program itself may have led to significant increases in rates of STI screening, (through greater detection of gonorrhea), rather than improved access to EC leading to riskier sexual behavior. In addition, they also observed that the population-level effect of EC on abortion rates may be unrealistic, particularly since many acts of sex are unprotected and EC is not always used.

Because EC prevents unwanted pregnancies, efforts to mainstream the method could be justified on the grounds that its use could be seen as an intervention to reduce maternal morbidity and mortality associated with unsafe abortions and other causes. Abortion is a frequent consequence of unintended pregnancy and, in the developing world, can result in serious, long-term negative health effects including infertility and maternal death. Regardless of the cause, unintended pregnancy and its negative consequences can be prevented by access to contraceptive services including emergency contraception. Addressing unintended pregnancy and its substantial human and dollar costs should be a priority

\section{BOX 1 EXAMPLES OF CONTRACEPTIVE FAILURE OR INCORRECT USE}

Condom breakage, slippage, or incorrect use;

Three or more consecutively missed combined oral contraceptive pills;

The progestogen-only pill (minipill) taken more than three hours late (or more than 12 hours late if taking a $0.75 \mathrm{mg}$ desogestrel-containing pill);

Norethisterone enanthate (NET-EN) progestogen-only injection taken more than two weeks late;

Depot-medroxyprogesterone acetate (DMPA) progestogen-only injection taken more than four weeks late;

The combined estrogen-plus-progestogen monthly injection taken more than seven days late;

Dislodgement, delay in placing, or early removal of a contraceptive hormonal ring or skin patch;
Dislodgement, breakage, tearing, or early removal of a diaphragm or cervical cap;

Failed withdrawal (e.g., ejaculation in the vagina or on external genitalia);

Failure of a spermicide tablet or film to melt before intercourse;

Miscalculation of the periodic abstinence method, or failure to abstain or use a barrier method on the fertile days of the cycle;

Expulsion of an intrauterine contraceptive device (IUD) or hormonal contraceptive implant.

Source: Levine, Ruth, Ana Langer, et al. 2006. "Chapter 57: Contraception," in Dean T. Jamison et al. (eds.), Disease Control Priorities in Developing Countries, Second edition. Washington, DC: The International Bank for Reconstruction and Development/The World Bank, pp. 1975-1990. 
in every country. Women and adolescents require access to age-appropriate and culturally sensitive reproductive health care services, including emergency contraception which is necessary in order to impact the staggering maternal mortality rates worldwide. ${ }^{4}$

In addition to the health-related arguments in favor of the use of emergency contraception, other researchers cite other reasons (which are applicable to contraceptives in general). For instance, Levine et al. ${ }^{5}$ state that three rationales have underlain policy and programmatic interest in contraception, since the 1960s:

- The demographic rationale, typically framed around lowering the rate of population growth to achieve broad economic, social, and environmental aims, was most prominently applied in the 1960s and 1970s. By helping to avoid unplanned pregnancies, use of emergency contraception contributes to this rationale.

- The fertility rationale, which emerged in the 1980s, promoted lower fertility under the assumption that smaller families are better off in terms of economic and health conditions.

"The human rights rationale, which surfaced in 1994 at the International Conference on Population and Development in Cairo, served as a major force in the 1990 s to focus attention on women's rights to autonomy and empowerment in childbearing and on female and male reproductive health. The Cairo Program of Action stressed the political and cultural dimensions of contraception, including gender issues. In many countries, health policies and constitutional provisions stipulate and confer the citizens' fundamental rights to enjoy the highest standards of health care including reproductive health. The choice regarding whether or not to have children, when to have them, or to postpone is part of the broad range of choices that exist under the human rights rationale.

In addition, published evidence demonstrates convincingly that making ECPs more widely available does not increase risk-taking or adversely affect regular contraceptive use. ${ }^{6}$ In the four studies that examined the impact of easier access to ECPs on rates of sexually transmitted infections, women randomly assigned to a group given advance supplies of ECPs for later use should the need arise had the same incidence of infection as did women in the control group who had to obtain ECPs from a clinic. For example, in one randomized trial considering the effect of advance ECP provision on regular methods of birth control, teens receiving emergency contraception supplies in advance were more likely to use ECPs when needed but did not report higher frequencies of unprotected sex, did not use condoms or hormonal contraception less often, and did not exhibit higher rates of STIs. ${ }^{7}$ Another study demonstrated that educating teens about ECPs does not increase their sexual activity levels or use of EC but increases their knowledge about proper administration of the drugs. ${ }^{8}$

From a global perspective, EC has yet to reach its full potential: many remain unaware that the option exists and $\mathrm{EC}$ remains difficult for most women to access in a timely fashion. Much work still remains to ensure that EC is available, especially in developing countries, and that unreasonable prescription requirements are re-examined. Evidence from recent demographic and health surveys in sub-Saharan Africa shows that contraceptive use is still low and that:

A high proportion of births (up to 50 percent) are
mistimed or unwanted.

A low proportion of women have "ever heard" or "used" EC. For instance, only $40 \%$ of women in Kenya have ever heard of EC and $1.7 \%$ had ever used EC. ${ }^{9}$

There is a limited capacity within public and private sectors for counseling about EC and correct provision (low proportion of health care providers trained on EC use).

Misinformation and negative media coverage persist, leading to misuse and stigma among those who request a method of EC.

\section{Guiding Principles}

Guiding principles for the improvement of health in general, and SRH in particular, have been adopted or reconfirmed at international assemblies and conferences and laid down in international documents including the Report of the International Conference on Population and Development (Cairo, 5-13 September 1994); and the "Overall Review and Appraisal of the Implementation of the Program of Action of the International Conference on Population and Development," presented to the General Assembly of the United Nations, 1 July $1999 .{ }^{10}$

Principles that have guided the development of the toolkit are:

Health is a fundamental human right. Everyone has the right to the highest attainable access to health care services, including those related to reproductive health care, which includes family planning and sexual health.

Commitment to the ethical concepts of equity, solidarity, and social justice and to the incorporation of a gender perspective in SRH strategies by policymakers, program managers, providers, and other implementers. This includes solidarity in action between countries, between groups in countries, and between sexes.

Ensuring that all health services are based on scientific evidence, of good quality, and within affordable limits, and that they are sustainable for the future. 
All couples and individuals have the basic right to decide freely and responsibly the timing, number, and spacing of their children and have access to information and education in order to ensure optimal health and informed decisionmaking.

- All people have the right to decide freely and responsibly on all aspects of their sexuality, and have the right to be free from conditions that interfere with sexual health; sexually acquired conditions including sexually transmitted infections (STIs) and HIV/AIDS; and coercion into having sex and other forms of sexual violence.

- The process of initiating emergency contraception should be participatory with a broad selection of participants or stakeholders.

- The toolkit acknowledges that ECPs are a back-up method for unprotected intercourse or contraceptive method failure and, as such, represent one of a range of contraceptive methods available to national programs. Therefore, the introductory process should ensure that ECPs are included in the program's overall training materials as well as in the logistics and distribution systems.

Reproductive health care must be responsive to expressed needs of the consumers. Individuals have both rights and responsibilities in promoting their own health and development. Similarly, governments have responsibilities for stewardship in the provision of health services.

- The provision of reproductive health services is enhanced by policies and programs that promote gender equity and equality, empower women, integrate the provision of RH/HIV services, and eliminate all forms of gender-based violence and discrimination.
Gender equity and equality must be addressed at all levels of service delivery, including generating and sharing information and in monitoring and evaluation (M\&E) activities. Involvement of men as RH consumers and responsible partners to women will increase access to and use of $\mathrm{RH}$ services, including prevention of unintended pregnancy.

There are many providers of EC services besides the Ministry of Health $(\mathrm{MOH})$ and its agencies. These include chemists and pharmacies in the private sector, NGO and FBO facilities, other departments of government such as the police (e.g., Zambia, South Africa). Efforts to improve EC provision within countries should consider all the potential stakeholders.

- The conceptual framework for mainstreaming EC activities is not prescriptive; rather it allows each country to freely make adaptations to it based on the local reproductive health policies and regulatory framework.

Given that the use of emergency contraception provides a second chance to women who have had unprotected sex, policymakers, program managers, regulatory authorities, pharmacy staff, and other health care providers should strive to minimize all barriers that could prevent women from accessing and using these pills and other products for EC. Given that the method using pills is controlled by the woman, this autonomy should be respected by society through user-friendly information materials and services.

- Introduction of EC mainstreaming activities and rollout should be coordinated and integrated with other services and programs to capitalize on existing infrastructure and program efforts especially in the public sector. 


\section{SECTION C}

The toolkit is designed to assist policymakers, program managers, and health care providers identify the most strategic opportunities for introducing EC mainstreaming activities in their respective settings and preferably within existing RH/FP programs. This toolkit is not designed as a detailed assessment tool. Numerous excellent assessment guides and programming tools have been developed to design EC programs and services, in the context of larger family planning programs and GBV activities. Most of these tools are available from the ICEC (www.cecinfo.org), Princeton University (ec.princeton.edu/ emergency-contraception.html), and the Population Council (www.popcouncil.org).

\section{Intended Audience}

Below is an illustrative list of potential country-level stakeholders to be involved in the process of mainstreaming emergency contraception:

Policy decisionmakers and program planners

Program managers, supervisors, providers of various $\mathrm{RH}$ services

Managers of commodity security and logistics

Key training institutions

- NGO, faith-based, private, and professional organizations, particularly those focused on family planning and other reproductive health activities

- Women's advocates and advocates for vulnerable populations

Institutions involved in social marketing or other communication initiatives

Development partners, including donors and technical assistance agencies
Pharmaceutical societies

Regulatory boards or councils responsible for drug registration and pharmacovigilance activities

Private sector pharmaceutical distributors

Representatives of chemists and pharmacies

Producers of EC products

Health care providers responsible for services designed to reach young people (girls/young women particularly), including school and university-based health clinics.

\section{Steps Involved in Mainstreaming EC Services}

Following proper steps is key to successful development and implementation of emergency contraception mainstreaming activities. Any country or subnational entity wishing to develop an emergency contraception program should be guided by the following steps or process activities: Preparation and awareness-creation, rapid assessment, sharing findings and reaching consensus on priorities, and developing a plan of action. Other steps include developing health system tools, training providers, introducing emergency contraception pills (ECPs), monitoring and supervision, program review and evaluation, dissemination of results, and scaling up and strengthening program sustainability. These steps are detailed in Table 1 below. Although the steps are organized chronologically, several actions within each broad step do overlap and may also be revisited over time. 


\begin{tabular}{|c|c|}
\hline EPS & 's \\
\hline $\begin{array}{l}\text { A. Preparation, advocacy, } \\
\text { and creation of aware- } \\
\text { ness }\end{array}$ & $\begin{array}{l}\text { This step involves organizing meetings of key persons or officials in the departments responsible for reproduc- } \\
\text { tive health matters including FP and those responsible for registration and regulation of drugs as well as } \\
\text { distribution of FP commodities. The purpose of this step is to agree on the main issues and next steps }\end{array}$ \\
\hline B. Rapid assessment & $\begin{array}{l}\text { Rapid assessment of emergency contraception service needs, regulatory requirements, and service delivery } \\
\text { capabilities among other things is a critical step in the provision of information to guide the mainstreaming } \\
\text { plan for an EC program. Important activities during the assessment include: } \\
\text { - Identifying factors that influence patterns of choice and potential use of ECPs in both public and private } \\
\text { sectors; } \\
\text { - Understanding user perspectives on ECPs and the service delivery system; } \\
\text { - Identifying the service delivery and managerial adaptations necessary to provide quality ECP services; } \\
\text { - Assessing providers' knowledge, attitudes, and practices on EC; and } \\
\text { - Using the outcomes of these activities to develop national strategies for the introduction and subsequent } \\
\text { widespread availability of ECPs. }\end{array}$ \\
\hline $\begin{array}{l}\text { C. Sharing findings and } \\
\text { reaching consensus } \\
\text { on priorities }\end{array}$ & $\begin{array}{l}\text { Involving a broad range of stakeholders to participate in sharing the results of the rapid assessment is an } \\
\text { important strategy for cultivating ownership. For instance, the pharmaceutical society could make presenta- } \\
\text { tions on findings from the private sector while government officials could make presentations on findings from } \\
\text { the public sector facilities. } \\
\text { Findings on user perspectives could be presented by a research institution. This participatory approach also } \\
\text { presents a good opportunity for identifying various skills among in-country teams. A key step in consensus- } \\
\text { building is for the in-country team to choose the type of EC pill such as Postinor } 2 \text { and discuss procurement } \\
\text { plans. In-country teams are advised to choose products that are already registered in the country. }\end{array}$ \\
\hline $\begin{array}{l}\text { D. Developing a plan of } \\
\text { action }\end{array}$ & $\begin{array}{l}\text { After reviewing the findings from the rapid assessment, the next logical step for the in-country teams is to } \\
\text { develop a plan of action based on the agreed priority activities. In-country teams are encouraged to review the } \\
\text { conceptual framework (Figure 1) so as not to overlook any sector that is crucial in mainstreaming EC. }\end{array}$ \\
\hline $\begin{array}{l}\text { E. Strengthening health } \\
\text { system tools (e.g., } \\
\text { registers, stock cards, } \\
\text { others) }\end{array}$ & $\begin{array}{l}\text { In order to track progress regarding the mainstreaming of EC, existing tools-e.g., family planning registers, } \\
\text { stock cards, reporting forms-will have to be modified or redesigned to incorporate additional columns that } \\
\text { health care providers will use to enter EC-related data. This step should also include the development of job } \\
\text { aids or mass media messages for clients on how to use ECPs and where to obtain them, among others. }\end{array}$ \\
\hline F. Training providers & $\begin{array}{l}\text { Providers will need training in issues related to the provision of ECPs, including the special counseling needs } \\
\text { of ECP clients. Of key importance is ensuring that providers treat women respectfully and maintain a nonjudg- } \\
\text { mental attitude while providing services. The training related to ECP service delivery provides an opportunity } \\
\text { to strengthen provider knowledge and skills concerning other contraceptive methods; the importance of their } \\
\text { routine use; and sexually transmitted infections (STIs/HIV risk) assessment, diagnosis, and management. } \\
\text { Information on ECPs must also be incorporated as part of overall training on family planning, including all } \\
\text { basic and refresher training for service providers. It must be stressed in all training activities, however, that EC } \\
\text { does not protect against STIs/HIV or subsequent unprotected intercourse. }\end{array}$ \\
\hline $\begin{array}{l}\text { G. Introd } \\
\text { distrib }\end{array}$ & $\begin{array}{l}\text { This step focuses on introducing ECPs into the market and distributing them through acceptable or author- } \\
\text { ized channels so as to reach clients. In addition to the normal family planning program service delivery } \\
\text { points, such as MCH/FP clinics and community-based distribution systems, the distribution of ECPs should be } \\
\text { considered through a variety of other channels. These include private health practitioners, hospital emergency } \\
\text { rooms, pharmacies, social marketing programs, school or university-based clinics, and sexual assault crisis } \\
\text { centres. }\end{array}$ \\
\hline $\begin{array}{l}\text { H. Monitoring and } \\
\text { supervision }\end{array}$ & $\begin{array}{l}\text { Monitoring and supervision should be conducted routinely to assess key components of the program including } \\
\text { the functioning of the logistics system, provider activities, whether users are accessing ECPs, and emerging } \\
\text { challenges, among others. }\end{array}$ \\
\hline I. Program evaluation & $\begin{array}{l}\text { Evaluation activities should include assessments of user and provider perceptions and experiences with ECPs } \\
\text { and of the service delivery channels through which they are being provided. Evaluation activities can assist in } \\
\text { ensuring that ECPs are used appropriately and serve as a bridge to regular FP for clients who require it. }\end{array}$ \\
\hline $\begin{array}{l}\text { J. Dissemination of } \\
\text { results }\end{array}$ & $\begin{array}{l}\text { - The evaluation results should be disseminated to a broad group of stakeholders. } \\
\text { - The results should form the basis of developing strategies for scaling up EC provision with emphasis on } \\
\text { the need to enhance quality EC services. }\end{array}$ \\
\hline $\begin{array}{l}\text { K. Scaling up and } \\
\text { strengthening program } \\
\text { sustainability }\end{array}$ & $\begin{array}{l}\text { In-country stakeholders will, on the basis of evaluation results, plan for the scale up of EC mainstreaming activi- } \\
\text { ties in other parts of the country so as to increase national coverage. Such a plan has to be agreed upon by } \\
\text { many stakeholders given its financial and administrative implications. } \\
\text { The interest of in-country stakeholders including } \mathrm{MOH} \text { in sustaining EC activities is to ensure that current pro- } \\
\text { gram activities and the proposed ones together with the benefits they produce are continued long after the } \\
\text { initial funding would have stopped, especially from development partners. Hence the need for in-country teams } \\
\text { to develop sustainable FP programs including EC. Such programs should consider taking into account factors } \\
\text { such as the need to provide high-quality services, providing management support for activities such as planning } \\
\text { and supervision, ensuring broad-based commitment by policymakers and public-private partnerships which } \\
\text { are critical elements in ensuring EC program sustainability. }\end{array}$ \\
\hline
\end{tabular}




\section{SECTION D INSTITUTIONAL FRAMEWORK AND}

IMPLEMENTATION MECHANISM

Many countries have three levels of health care management and coordination. These are national, regional, and district levels. The national level is responsible for policy and stewardship, the regional level is usually responsible for coordination, training, and quality assurance while the district level is responsible for managing implementation. Delivery of health care services also happens at the service delivery point and at the community level.
Successful mainstreaming of EC activities at the country level has to take into account the potential role of national, regional, and district levels and in particular how these levels will play complementary and supportive roles to each other. These roles are outlined below in Table 2 with regard to emergency contraception mainstreaming activities.

\section{TABLE 2 ROLES OF VARIOUS INSTITUTIONS IN MAINSTREAMING EMERGENCY CONTRACEPTION AC-} TIVITIES BY LEVEL OF HEALTH CARE MANAGEMENT AND COORDINATION

\begin{tabular}{|c|c|c|}
\hline NATIONAL LEVEL & $\begin{array}{l}\text { REGIONAL/PROVINCIAL/ } \\
\text { COUNTY LEVEL }\end{array}$ & DISTRICT/COMMUNITY LEVEL \\
\hline $\begin{array}{l}\text { - Develop reproductive health policies } \\
\text { - Provide leadership, advocacy, and coordi- } \\
\text { nation of reproductive health activities at } \\
\text { all levels and among stakeholders. } \\
\text { - Establish procedures, and adopt required } \\
\text { regulations, standards, and guidelines } \\
\text { - Disseminate and distribute policy briefs } \\
\text { and discussion papers on emerging EC } \\
\text { mainstreaming issues } \\
\text { - Advocate for increased funding for RH } \\
\text { including family planning activities } \\
\text { - Assess the safety, efficacy, and quality of } \\
\text { drugs and medical devices } \\
\text { - Lead/coordinate/monitor and evaluate EC } \\
\text { mainstreaming activities } \\
\text { - Organize periodic forums for disseminat- } \\
\text { ing results and experiences } \\
\text { - Develop training curriculum manuals and } \\
\text { advocacy materials on EC for distribution } \\
\text { at subnational levels }\end{array}$ & $\begin{array}{l}\text { - Supervise } \\
\text { - Monitor } \\
\text { - Train } \\
\text { - Quality assurance } \\
\text { - Coordinate monitoring } \\
\text { and evaluation of EC } \\
\text { mainstreaming activities } \\
\text { - Disseminate national } \\
\text { guidelines, policies, } \\
\text { standards, among } \\
\text { others } \\
\text { - Carry out pharmacovigi- } \\
\text { lance activities } \\
\text { - Organize periodic fo- } \\
\text { rums for disseminating } \\
\text { results and sharing EC } \\
\text { mainstreaming activi- } \\
\text { ties in the region }\end{array}$ & $\begin{array}{l}\text { - Facilitate identification of providers dispensing ECPS } \\
\text { - Assess premises that stock ECPs } \\
\text { - Organize capacity-building and continuing } \\
\text { - Ensure re-supply of ECPs and other family planning } \\
\text { commodities } \\
\text { - Provide supportive supervision to health facilities } \\
\text { - Mobilize local resources to support RH/FP activities } \\
\text { - Compile monitoring data and produce periodic reports } \\
\text { - Review community level IEC/BCC materials for } \\
\text { relevance and appropriateness } \\
\text { - Facilitate dialogue between community and health } \\
\text { service providers } \\
\text { - Strengthen community involvement in decisionmaking } \\
\text { about EC services } \\
\text { - Establish a link between the health sector and the } \\
\text { community } \\
\text { - Identify cultural beliefs and practices that influence } \\
\text { health care-seeking behavior } \\
\text { - Quantify requirements for FP including ECPs and } \\
\text { place requisitions as per national schedules and } \\
\text { requirements }\end{array}$ \\
\hline
\end{tabular}




\section{SECTION E MANAGEMENT OF FP/EC LOGISTICS}

Proper management of any logistics system is to ensure that goods including ECPs or services such as counseling or information and education reach the intended clients at the right time and place. Key messages that are appropriate to many logistics management systems including the delivery of ECPs are outlined Text Box 2.

\section{Components of inventory management}

Implementation experience has demonstrated that managers involved in procuring, storage, and distribution of $\mathrm{FP} / \mathrm{RH}$ commodities including ECPs need to pay attention to the following components of inventory control:

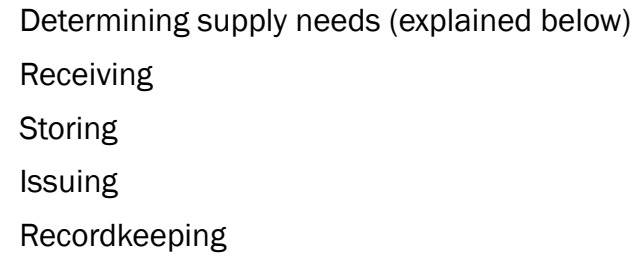

\section{Determining Supply Needs}

Determining supply needs is one of the most important steps in inventory management.

\section{BOX 2 KEY MESSAGES FOR EFFECTIVE LOGISTICS MANAGEMENT SYSTEM FOR ECPS*}

- The logistics six rights provide that good logistics deliver: the right product, in the right quantity, in the right condition, to the right place, at the right time, and for the right cost. The "right logistic management information system" to enable the delivery of the six rights possible could be considered the seventh right.

- The purpose of a logistics management information system is to collect, organize, and report information to other levels in the system in order to make decisions regarding the quantity and the time needed to distribute drugs, contraceptives, and related medical supplies.

- Procurement, recording, and reporting are important functions of any logistics management system

- All personnel at all levels are important in making the logistics system work effectively.

- An effective logistics system will ensure that facilities are adequately stocked at all times and that medical supplies including ECPs are available when needed.

If staff carry out their responsibilities to the best of their abilities, then the seven "rights" will be achieved.

\section{Components of a Logistics System}

- Serving the customer

- Product selection

- Forecasting and procurement

- Inventory management

- Logistics Management Information System (LMIS)

- Continuous monitoring

Items that any logistics management information system needs to capture are:

- Stock on hand: quantities of usable stock at any level of the system (or facility) at a particular point in time.

- Consumption data: the quantity of commodities dispensed or used during a particular period of time.

- Data on losses and adjustments: the quantity of commodities no longer available for use, which have not been dispensed/used (e.g., damaged, expired, or stolen commodities), and transfers to or from other facilities.

*Source: Ministry of Health. 2008. Integrating Counselling and Testing for HIV into Family Planning Services, National Training Manual, 1st Edition. Nairobi: Ministry of Health. March. 
Once the necessary supply needs are identified and quantified, the next step is to reconcile these requirements with the available financial resources or budgetary commitment (from either the government or donors).

Once this is done then appropriate procurement processes are undertaken to facilitate the delivery of the commodities. More often the quantities of commodities procured under a public-sector program are dependent on the availability of financial resources allocated for this purpose by ministries of finance. The situation is slightly different in the private sector where the quantities procured or distributed are dependent on potential demand for the respective commodity or commodities.

Determining supply needs is done by conducting a physical inventory in order to review stock status. Other reasons for conducting a physical inventory include:

Determining how much of each commodity one has in the facility,

Determining how long the stocks will last, and

- Ascertaining whether the available quantities of stocks could last until the next order is received or processed.

Frequent review of stocks is important in estimating consumption of commodities and supply needs. Estimating consumption of commodities is done as follows:

- Calculate average monthly consumption

- Determine months of stock on hand

Determine order quantity (by estimating maximum and minimum stock levels, conducting physical counts [stock on hand] and subtracting the balance on hand from the maximum stock level to be able to obtain the quantity to order).

\section{Monitoring Monthly Consumption of ECP Stocks}

Monitoring monthly consumption of stock is an important step in establishing the quantity consumed or to be ordered. Managers involved in procurement, inventory control, and distribution of FP/RH commodities including ECPs need to be conversant with basic concepts concerning months of stock and how to derive maximum and minimum levels of stocks at different levels of inventory control. This is because central, regional, or district and health facilities require varying quantities of minimum and maximum months of stock.

\section{Months of stock}

This is the number of months supplies will last based on the present consumption rate. It is obtained by dividing the ending balance per month of stock (e.g., of ECPs) by the average consumption of stock (e.g., ECPs) per month.

\section{Maximum months of stock}

It is the largest amount of each commodity a facility should hold at any one time.

\section{Minimum months of stock}

It is the least amount of each commodity a facility should have at any one time.

Examples of the minimum and maximum months of ECPs by level of inventory control are given in Table 3. For purposes of illustration, only two levels are given, namely the central warehouse and the health facility.

\section{Stock card}

A stock card or, as it is sometimes called, a bin card is an important document that records the status of a good or goods held in a store or stockroom. The card helps in recording a running balance of stock (in our case the ECPs). Thus, the stock card (see an example in Figure 2) facilitates accounting for supplies requisitioned. In places where information is not computerized, it is stored at the service delivery point and is completed by the officer in charge each time new supplies are received. In places where inventory control has been computerized, the information on the stock card is updated electronically and it is possible to know the balance of the stocks on daily basis.

TABLE 3 MINIMUM AND MAXIMUM MONTHS OF ECPS BY LEVEL OF INVENTORY CONTROL

\begin{tabular}{|l|l|l|l|l|}
\hline \multirow{2}{*}{ COMMODITY } & $\begin{array}{l}\text { LEVEL OF } \\
\text { INVENTORY CONTROL }\end{array}$ & $\begin{array}{l}\text { MAXIMUM MONTHS } \\
\text { OF STOCK }\end{array}$ & $\begin{array}{l}\text { LEVEL OF INVENTORY } \\
\text { CONTROL }\end{array}$ & $\begin{array}{l}\text { MINIMUM MONTHS OF } \\
\text { STOCK }\end{array}$ \\
\hline $\begin{array}{l}\text { Contraceptives } \\
(\text { ECPS })\end{array}$ & Central warehouse & $12-15$ months & Central warehouse & $6-9$ months \\
\cline { 2 - 5 } & Health facility & $4-6$ months* & Health facility & $2-3$ months* \\
\hline
\end{tabular}

* Shorter periods of minimum and maximum months of stock are required to avoid possible losses, e.g., through expiry. 


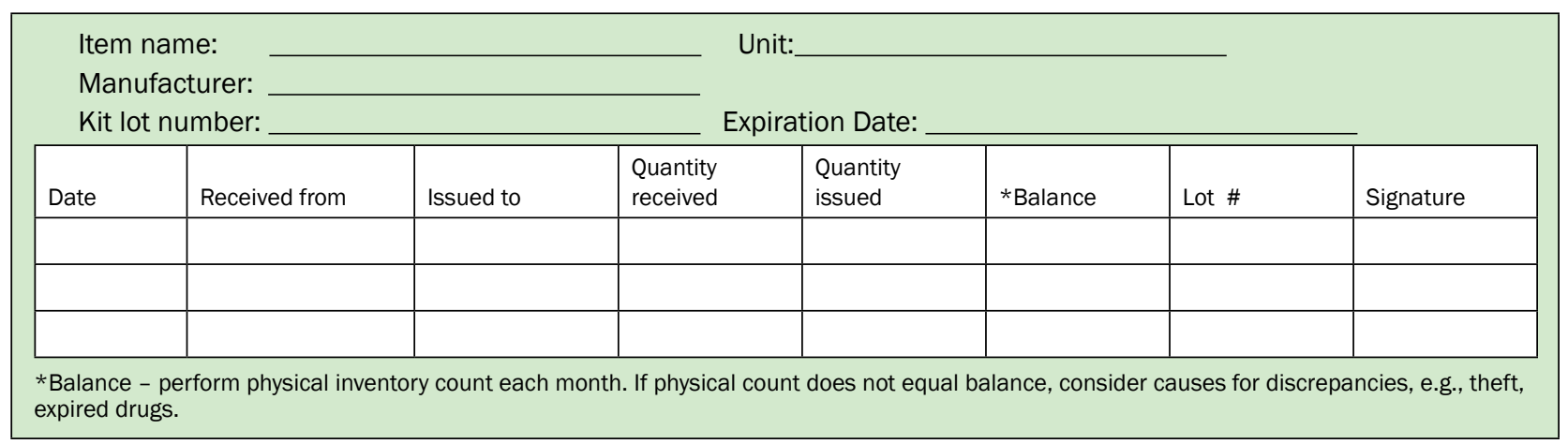

\section{Supervision}

Effective supervision is a critical element of an effective Logistics Management System (LMS). Without it, overall quality of LMS may weaken, which in turn may jeopardize the quality of service provided to clients. This is the process of ensuring that personnel have the knowledge and skills required to carry out their responsibilities effectively, and to provide immediate on-the-job training, as needed. Supervision ensures personnel have the knowledge and skills they need to effectively manage the logistics system and identifies performance weaknesses and improves performance through on-the-job training as needed.

Supervision also ensures that that established logistics guidelines and procedures are being followed. The team carrying out supervision activities should establish that each FP service delivery site including clinics and health posts shall:

- Have a copy of the policy guidelines and service standards for sexual and reproductive health. Some of these policies also address the provision of EC services.

- Have a copy of family planning procedures guidelines for service providers. National FP guidelines usually address issues to do with the provision of EC services.

- Maintain adequate and accurate records of clients and commodities.

- The monthly supervision and monitoring tool for ECPs is found in Appendix A.7. 


\section{Monitoring and Evaluation Activities}

Efforts for mainstreaming emergency contraception are likely to be undermined by two main challenges. First, monitoring the use of emergency contraception pills by clients in the private sector (including chemists, pharmacies, and clinics) is a difficult task since the majority of providers do not maintain good records. Second, monitoring the use of emergency contraception pills in the public sector is sometimes difficult due to low volume used coupled with poor reporting rates by health facilities.

In some countries, FP commodity utilization register(s) and gender-based violence registers are the main sources of data on ECPs in the public sector. In some countries, the police department or other office in the justice system could also serve as a source of data for ECPs, especially those stocks used for gender-based violence cases. In countries where $\mathrm{CHWs/CBDs}$ are allowed to distribute ECPs, one could also find utilization data from their records. In the private sector, good estimates of the use of ECPs at the population level have been derived from sales data (obtained from the distributors of brands of dedicated ECPs such as Postinor 2). ${ }^{11}$

The most likely sources of data for program evaluation are:

a) Demographic and Health Survey (DHS): The DHS is a nationally representative household survey that is the source of impact and outcome indicators.

b) Service Provision Assessment (SPA): The SPA is a nationally representative facility survey that collects information on aspects of out-patient primary care (i.e., antenatal, family planning, and sexually transmitted infections) services and providers.

c) Surveillance: Surveillance is the ongoing, systematic collection, analysis, and interpretation of data on a disease or health condition from public health programs, combined with feedback to all. It is vital for guiding the national response. d) Evaluations: Evaluations are conducted to gather evidence on whether the right interventions are being (or were) implemented with recommendations/lessons learned and whether the program effects could be attributed to specific interventions.

\section{Pharmacovigilance}

Pharmacovigilance refers to the science of collecting, monitoring, researching, assessing, and evaluating information from health care providers and patients on the adverse effects of medicines, biological products, herbals, and traditional medicines. Pharmacovigilance is an arm of patient care whose aim is to promote patient safety by identifying new information about hazards and preventing harm to patients. Its scope includes substandard and counterfeit medicines, medication error reporting, adverse interactions of medicines, etc. Although this activity is usually conducted by regulatory authorities, our implementation experience shows that dealing with counterfeit ECPs has often required team effort by stakeholders involved in EC mainstreaming work.

\section{Signs of a poor-quality medical product}

Identifying and dealing with counterfeit ECPs (especially the dedicated brands) is often a complex exercise. However, regular surveillance activities by a team from regulatory authorities, law enforcement officers, and public health officials, among others, are often effective in minimizing this problem.

Box 3 provides a list of examples of signs of a poorquality medical product that does not meet the required quality standards in terms of physical appearance, level of active ingredients, packaging, and labeling which the surveillance teams are likely to look for. Other measures such as officials from regulatory bodies (in a country where new ECPs are to be registered) visiting manufacturing sites to assess whether the firms involved do follow strictly good manufacturing practices and periodic changes to packaging materials and instructions help in addressing quality concerns. 


\section{BOX 3 SIGNS OF A POOR-QUALITY MEDICAL} PRODUCT

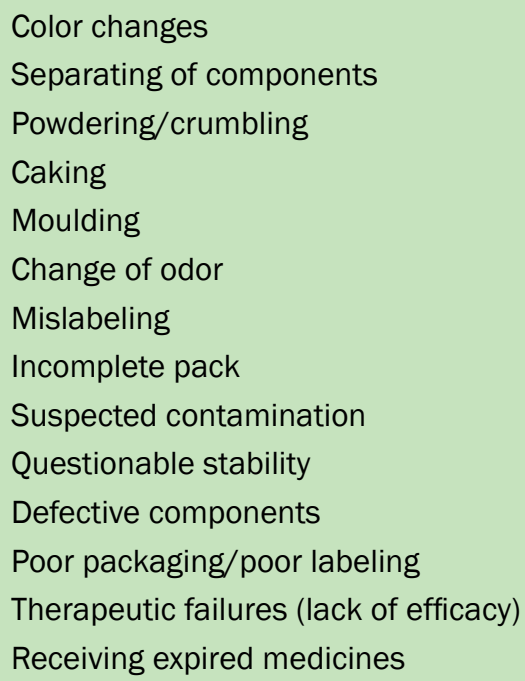

WHO. 2002. The Importance of Pharmacovigilance - Safety monitoring of medicinal products. Geneva: WHO.

\section{Indicators for Assessing Performance of FP/ECPs Logistics System}

In 2007, the RH Supplies Coalition developed a Monitoring and Evaluation Framework 2007-2015, ${ }^{12}$ which contains a list of 30 key indicators for tracking progress for $\mathrm{RH}$ supplies. In this toolkit, some of the indicators have been adapted for use by countries wishing to track the EC mainstreaming work. See Appendix A.8 for a full list of the indicators, which are organized around specific objectives and the following three goals:
Goal 1: Increase predictability and sustainability of financing for FP/EC supplies

Through this goal, the $\mathrm{RH}$ partners, including $\mathrm{MOHs}$ aim to increase resource flows for FP commodities including EC supplies from all sources at the country level. Possible sources include donors, consumers, the public sector, insurance schemes, and the private sector.

\section{Goal 2: Strengthen the capacity of health systems to sustain FP/EC supplies}

This goal aims to maximize synergies among $\mathrm{MOH}$ partners in order to strengthen supply chain systems and ensure sustained delivery of a broad range of RH supplies including FP commodities. Strengthening the capacity of health systems to deliver FP/EC supplies will encompass both public and private sector institutions.

\section{Goal 3: Steer EC mainstreaming activities within the broader $\mathrm{RH}$ services}

This goal seeks to reinforce the capacity of the $\mathrm{MOH}$ and its partners to advocate for $\mathrm{RH}$ supplies security (including FP/EC commodities), promote innovation and an all-inclusive approach in creating awareness, and in conducting advocacy activities. The goal also seeks to expand the total market for FP commodities including EC pills and identify other sustainable ways of mainstreaming EC such as training, policy support, creating awareness at all levels, and integrating EC mainstreaming in the broader $\mathrm{RH}$ activities. 


\section{Awareness and Use of ECPs Increased During the Project Period}

Awareness and reported use of ECPs increased dramatically over the life of the initiative. In 2003, the KDHS indicated that less than one quarter of Kenyan women had ever heard of ECPs. ${ }^{13}$ In 2007, PSI conducted a baseline survey in 13 major towns and peri-urban areas across seven provinces, and found similar patterns, with only $21 \%$ of women reporting having ever heard of ECPs and $5 \%$ who had ever used the method. Of those, only $15 \%$ could correctly identify ECPs as a contraceptive method taken after sex to prevent pregnancy. By $2009,56 \%$ of women in the same sites had ever heard of ECP and $10 \%$ had ever used the method. ${ }^{14}$

Despite huge increases in the proportion of clients who had heard of or ever used ECPs, the overall utilisation rate is still low, indicating the need for continued education and awareness-creation. Countries wishing to implement EC mainstreaming activities need to appreciate the fact that a major restriction on women's use of EC is their very low rate of awareness of this FP method. Because EC is generally accessed at the pharmacy level in Kenya women must know about it in order to seek it out. In this regard, EC differs significantly in the commodity and supply chain issues from other methods such as implants and female condoms which are described in detail by the United Nations Commission on Life-saving Commodities for Women and Children. ${ }^{15}$

The results are consistent with views recently expressed by Westley and Swartz ${ }^{16}$ who pointed out that EC has yet to reach its full potential in terms of impact. EC remains difficult for most women to access in a timely fashion, and the most effective methods of EC such as dedicated ECPS are even harder to access compared to Yuzpe methods. Dedicated ECPs are effective in preventing up to $95 \%$ of pregnancies, and the Yuzpe method is effective in approximately $75-80 \%$ of cases.

\section{Mainstreaming the Provision of EC in the Private Sector}

Findings from the EC mainstreaming project in Kenya showed that private-sector pharmacies are the most common access point for ECPs. PSI's 2007 baseline survey found that $94 \%$ of women who had used ECP in the past two years obtained it from pharmacies. In 2009 , their endline survey found that while $83 \%$ identified pharmacies as a place to obtain ECPs, only $25 \%$ mentioned government clinics. ${ }^{17}$ In 2008, national-level ECP distribution through private sector pharmacies was approximately twice that distributed through the public sector. Within government clinics, a 2007 record review found that $93 \%$ of the ECPs distributed in the previous 18 months were for sexual assault cases. ${ }^{18}$ This shows a possible bias toward the use of EC in cases of sexual assault when compared to other more common indications that exist within many public health facilities.

In countries where the coverage of the private sector is not significant in health, such biases in the provision of EC services by the public sector may imply that women wishing to have access to it may not succeed because of the limited options other than in cases of sexual assault. Therefore, countries wishing to embark on EC mainstreaming activities need to plan carefully well in advance on how to position ECPs to avoid stigmatizing this critical service.

Given the key role pharmacies play in the provision of EC services, evidence shows that when pharmacy staff are given basic information on key messages they need to give their clients, they did provide the information on EC (including when and how to use it, mechanism of action, side effects, and efficacy). The pharmacy staff also discussed other FP and $\mathrm{RH}$ services with clients. These results suggest that sales staff at private sector pharmacies can deliver more effective EC services when given the proper tools. It also indicates that extensive and often costly training efforts are not needed to improve services within pharmacies. ${ }^{19}$

\section{Strengthening the Provision of EC in the Public Sector}

Four main lessons emerged from the implementation experience in mainstreaming EC activities in Kenya. These lessons (highlighted below) revolve around developing simple-to-use reference materials for health care providers, integrating ECPs into pre-service and in-service training programs, advocacy activities at the policy level, and strengthening of data-capture tools (registers). 


\section{Materials development for health care providers}

To support training efforts, a comprehensive PowerPoint presentation on EC was developed for trainers as well as a booklet, the Health Care Providers Quick Reference Guide, published as part of a strategy to enable as many health care providers as possible to have access to user-friendly and updated materials on emergency contraception. The booklet was also disseminated widely to provincial and district health management teams by the $\mathrm{MOH}$ and was used as source material for the 2010 update of the National FP Guidelines. Simple and easy-touse materials-especially those that fit into pockets of lab coats-are preferred by health care providers. Because of its simplified language, the $\mathrm{MOH}$ in Kenya also distributed thousands of copies of the Health Care Providers Quick Reference Guide booklet to members of the public. ${ }^{20}$

\section{Integrating ECPs into pre-service and in-service training programs}

With minimal resources, modules on ECPs were inserted into in-service training packages for use by health care providers in Kenya. In addition EC modules were incorporated into the Nursing Council's and Clinical Officers' pre-service training curricula. Incorporating EC into the pre-service training curricula ensures that all future nursing and clinical medicine graduates will receive instruction on ECPs and the strategy was seen as a more cost-effective way of sustaining health care providers' knowledge and practice on emergency contraception. The approach also promotes the principle that EC should be addressed in the context of comprehensive FP/RH services rather than as a stand-alone service.

\section{Policy-level advocacy is necessary to ensure adequate ECP stocks in the public sector}

Under the leadership of the $\mathrm{MOH}$, advocacy efforts ensured that ECPs were included in the national contraceptive security plan and subsequent procurements. For instance in FY 2012/2013 the Government of Kenya has allocated approximately Kshs. 976,423,000 $(\$ 11,624,000)^{21}$ for the procurement of FP commodities, which is slightly over twice the amount of funds (Kshs. 350,000,000 $=\$ 5,147,059)^{22}$ that was allocated by the Kenyan government for the purchase of FP commodities during FY 2006/2007 at the beginning of the EC mainstreaming activities. These figures demonstrate the Kenyan government's commitment to sustaining the procurement of FP commodities using its own funds.

\section{Revision of FP registers and inclusion into the Contraceptive Security Strategy}

In 2008 the Division of Reproductive Health (DRH) in the $\mathrm{MOH}$ added a column for ECPs to the revised FP register to improve recordkeeping and allow facilities to reorder ECPs. Integrating EC into the documents that underpin contraceptive security such as the national FP register, ensured that EC utilization was properly recorded and captured in facility-level stock re-ordering alongside the other regular FP methods. Another important accomplishment regarding the EC mainstreaming effort was the inclusion of ECPs in the national contraceptive security strategy, which is intended to limit stock-outs of essential family planning commodities. This ensures that EC programming activities receive the requisite attention at all levels alongside the other regular FP methods.

\section{Ensuring Sustained Impact}

Although PSI's advocacy campaign was successful in generating momentum around $\mathrm{EC}$, at the end of the first phase of the EC mainstreaming project (2007-2009), stakeholders in Kenya felt that they still required technical assistance in developing strategies to institutionalize and sustain the achievements realized under this initiative. It was on the basis of this request that the Population Council, with support from the Hewlett Foundation, coordinated the second phase of the EC mainstreaming project (January 2010 to May 2012) with a focus on institutionalizing key activities to sustain the impact of the project. A detailed project description for the follow-up phase is found in the CD-ROM. Some of the key achievements during the follow-up project were:

Inclusion of EC into the Bachelor of Science in Nursing (BScN) syllabus in 2010. The BScN syllabus is administered by the Nursing Council of Kenya. In 2011, the curriculum for the Diploma in Clinical Medicine and Community Health $(\mathrm{DCMCH})$ that is administered by the Clinical Officers' Council was revised to incorporate new topics including EC.

Strengthening the provision of EC in public-sector health facilities by provincial and district level health management teams through structured support supervision visits.

Approval of the EC selling protocol, in February 2011, by the Pharmaceutical Society of Kenya (PSK), for use by their members to strengthen provision of EC services in the private sector pharmacies.

Successful completion of a South-South technical exchange visit that involved four sub-Saharan African countries that were interested in mainstreaming emergency contraception activities. The three-day visit took place in early April 2012 and involved health managers from Rwanda, Malawi, Uganda, and Zambia. During the meeting, delegates shared experiences in mainstreaming EC in their respective countries with their Kenyan counterparts. The teams also visited private-sector pharmacies (to see how ECPs were provided in the private sector) and the Kenya Medical Supplies Agency (KEMSA) to familiarize themselves 
with procurement procedures for FP supplies including ECPs, storage, and countrywide distribution of these commodities to health facilities.

- The national communications campaign undertaken by PSI effectively increased awareness of EC among the target population. To expand the program's impact with limited resources, the Council worked with the MOPHS to ensure that EC messages are incorporated within the national communications strategy and that the materials from PSI's national mass-media Tulia campaign continue to be used by the $\mathrm{MOH}$.

Besides these achievements, ensuring a sustained impact of EC mainstreaming activities also requires that countries focus on the 5Ps of product, price, place, promotion, and people so that their product (or service) appropriately targets the chosen segment of the market. ${ }^{23}$

Product. How the product (or service) should look and function to meet the needs of the target audience(s). This includes considerations of packaging, branding, and product formulation. Dedicated EC products are specifically identified for emergency contraception and contain appropriate instructions as well as the required number of pills for their correct use. Specific packaging makes them easier to supply through pharmacies and social marketing programs. ${ }^{24}$

Price. What the product (or service) costs the direct consumer. This price should fit the target audience's ability to pay. In an earlier study in Kenya, the authors found out that nearly all university students interviewed were willing to pay for ECPs (Postinor 2) at an estimated price of \$1 (40 Kenya shillings at the 1996 exchange rate) rather than risk paying for abortion services, which cost over a hundred times more. The price for inducing an abortion was then estimated at ( $\$ 100$ or 4,000 Kenya shillings at the 1996 exchange rate).$^{25}$ Although ECPs are provided free of charge in public-sector facilities, the findings showed that availability of ECPs in private-sector outlets could be sustained through direct sales of the pills to clients.

Placement. Where the product (or service) is available. Placement should factor in the type of outlet (e.g., clinic, store, pharmacy) but also the operating hours of such outlets. Given that some of the private sector pharmacies in Kenya operate for 24 hours especially in urban areas, clients seeking to buy these commodities can theoretically access the services any time, compared to the restrictions found in the public sector regarding opening and closing hours and the unavailability of these services during weekends and public holidays (unless in the case of survivors of rape or gender-based violence).
Promotion. What advertising and communication channels are used to encourage consumer uptake of the product or service. PSI used a mass-media campaign on the radio, in print, and on TV (to increase awareness and knowledge of EC). In addition, other channels included developing point-of-sale materials, e.g., brochures to increase clients' knowledge and uptake of regular FP methods).

People. People need to bring products to customers or clients. The revised National FP Guidelines in Kenya ${ }^{26}$ allow various cadres of health care providers to handle ECPs. These include doctors, nurses, clinical officers, pharmacists, pharmaceutical technologists, pharmacy assistants, counselors, and community health workers, among others. For successful institutionalization and replication of EC mainstreaming activities, as a minimum, each of the persons involved in providing EC services to clients ought to emphasize these key messages:

- EC can prevent pregnancy after unprotected sex,

- EC does not protect against HIV or STI infection, and

- EC should be used only as an emergency method and not as a regular form of contraception

Other sustainability factors critical to ensuring the program's success are:

\section{Target-group knowledge, attitudes, and practice}

The degree to which the principal target groups are knowledgeable and motivated to utilize EC services and their benefits improves sustainability. Low knowledge, poor motivation, and non-use of services are a threat to sustainability.

\section{Service quality}

The degree to which high-quality services can continue to be provided in the future is an indicator of program sustainability. Low quality or the absence of key services can be a threat, while high quality may increase demand for services and support.

\section{Management support}

Management support for activities such as planning and supervision enhances the chance of sustaining programs. Weak or missing support services can be a threat to sustainability.

\section{Policymakers' commitments}

High, broad-based commitment by policymakers is conducive to sustainability; low, narrow-based com- 
mitment is a threat. A commitment by policymakers ensures the availability of the desired commodity and facilitates in-country registration allocation of resources for procurement, distribution, monitoring, and supervision activities. Policy commitment also builds effective partnerships and facilitates the development of appropriate standards, guidelines, and implementation of appropriate quality assurance activities.

\section{Notes}

1 Langer, A., et al. 1999. “Emergency contraception in Mexico City: What do health care providers and potential users know and think about it?" Contraception 60: 233-241.

2 Durrance, Christine Piette. 2012. "The Effects of Increased Access to Emergency Contraception on Sexually Transmitted Disease and Abortion Rates," Economic Inquiry. Western Economic Association International.

3 Moreau, Caroline, James Trussell, and Anna Glasier. 2012. "Challenging the 'insurance theory' of sexual and reproductive health behaviors," Journal of Contraception 85(1): 9-10.

4 Klima, Carrie S. 1998. "Unintended pregnancy: Consequences and solutions for a worldwide problem," Journal of Nurse-Midwifery 43(6): 483-491.

5 Levine, Ruth, Ana Langer, et al. 2006. "Chapter 57: Contraception," in Dean T. Jamison et al. (eds.), Disease Control Priorities in Developing Countries, Second edition. Washington, DC: The International Bank for Reconstruction and Development/The World Bank, pp. 1975-1990.

6 Shaaban, O.M., et al. Forthcoming. "Emergency contraceptive pills as a backup for lactational amenorrhea method (LAM) of contraception: A randomized controlled trial," Contraception.

7 Gold, M.A., et al. 2004. "The effects of advance provision of emergency eontraception on adolescent women's sexual and contraceptive behaviors," Journal of Pediatric \& Adolescent Gynecology (17): 87-96.

8 Graham, A. et al. 2002. 'Improving teenagers' knowledge of emergency contraception: Cluster randomized controlled trial of a teacher led intervention," British Medical Journal (234): 1179-1184.

9 Kenya National Bureau of Statistics (KNBS) and ICF Macro. 2010. 2008-09 Kenya Demographic and Health Survey. Calverton, MD: KNBS and ICF Macro.

10 WHO Regional Strategy on Sexual and Reproductive Health: Reproductive Health/Pregnancy Program (EUR/01/5022130). Copenhagen, Denmark, November 2001.

11 Keesbury, Jill, et al. 2009. Mainstreaming Emergency Contraception in Kenya: Final Project Report. Nairobi: Population Council, Nairobi and Population Services International, Kenya.

12 Reproductive Health Supplies Coalition (August 2007): Monitoring and Evaluation Framework 2007-2015.

13 Central Bureau of Statistics (CBS) et al. 2004. Kenya Demographic and Health Survey 2003. Calverton, MD: CBS et al.
14 Population Services International-Kenya (PSI). 2009. Mainstreaming EmergencyContraception in Kenya: Final Narrative Report. Nairobi: PSI.

15 Contraceptive Commodities for Women's Health - UN Commission. 2012. FP Synthesis_Final 19 March.

16 Westley, Elizabeth and Eleanor Bimla Schwarz. 2012. "Emergency contraception: Global challenges, New opportunities" (editorial), Contraception 85: 429-431.

17 Op. cit. note 14.

18 Keesbury, Jill, et al. 2009. Mainstreaming Emergency Contraception in Kenya: Final Project Report. Nairobi: Population Council, Nairobi and Population Services International, Kenya.

19 Obare, Francis, Jill Keesbury, and Wilson Liambila. 2010. "The provision of emergency contraceptives in private sector pharmacies in urban Kenya: Experiences of mystery clients." African Population Studies 24(1-2).

20 Op. cit. note 11.

21 Republic of Kenya. 2012. National Family Planning Costed Implementation Plan (2012-2016), Ministry Of Health.

22 Republic of Kenya. 2007. MOH Printed Estimates and VoteBook. Nairobi: Republic of Kenya.

23 Powers, Shane. 2009. "The 5Ps of Marketing." PowersBusiness.com.

24 International Consortium for Emergency Contraception (ICEC). 2013. "Introducing EC: A framework for designing an emergency contraception program" <http://cecinfo.org/ introducing-ec-a-framework/>. Accessed 1 February 2013.

25 Muia, E., et al. 2000. "What do family planning clients and university students in Nairobi, Kenya, know and think about emergency contraception?" African Journal of Reproductive Health 4(1): 77-87.

26 Republic of Kenya. 2012. National Family Planning Guidelines for Providers. Nairobi: DRH, MOPHS. 



\section{SECTION H APPENDICES}

H.1 - Project Overview and Summary of Results

H.2 - Health Care Providers Quick Reference Guide

H.3 - Selling Protocol for Emergency Contraception Pills

H.4 - Job Aid for Bridging EC Users to Other RH Services

H.5 - Hormonal Emergency Contraception

H.6 - WHO Fact Sheet on Emergency Contraception

H.7 - MOH Monthly Supervision and Monitoring Tool

H.8 - Key M\&E Indicators for FP commodities/EC Pills 


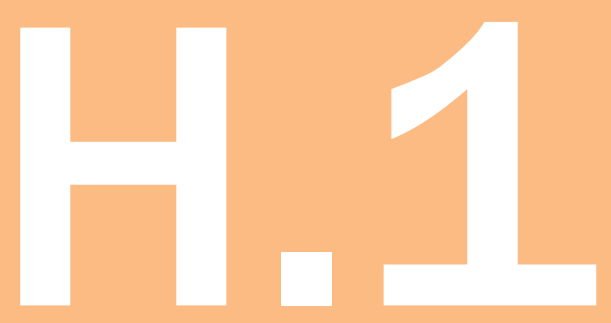

$$
\begin{aligned}
& \text { PROJECT } \\
& \text { OVERVIEW AND } \\
& \text { SUMMARY OF } \\
& \text { RESULTS }
\end{aligned}
$$




\section{Introduction}

mergency contraception (EC) is an important element of reproductive health care. EC is the
only family planning method that can be used to prevent pregnancy after rape or unpro-
tected sex. It does not cause abortion or harm to an existing pregnancy.

According to the 2003 Kenya Demographic Health Survey (KDHS), close to half of the births in the preceding 5 years were mistimed or unwanted. The preliminary results of the 2008 KDHS indicate that less than half (46\%) of currently married women were using some method of contraception; use was lowest among women between the ages of 15 and 24. Increased access to family planning, including EC, can reduce the number of unplanned pregnancies in the country and contribute to lower rates of abortion, child neglect, and abandonment.

Despite increased media attention, EC remains a highly underutilized method across Kenya. Recent data indicate that

"I think we have not adequately explained to the community that the morning-after pill should be used only in situations where people have accidentally had unprotected sex or in the case of sexual coercion."

- Dr. Shahnaaz Sharif, Director, Public Health and Sanitation, MOPHS only $56 \%$ of women of reproductive age had ever heard of EC. ${ }^{1}$ To improve access to the method and ensure that adequate information is provided to all users, the Ministry of Public Health and Sanitation (MOPHS), the Population Council, and Population Services International- Kenya (PSI) undertook a three-year effort to mainstream EC in Kenya, which was supported by the William and Flora Hewlett Foundation. This brief presents the results of this initiative, and discusses strategies for further strengthening EC provision in Kenya.

\section{What Is EC?}

"Emergency contraception" refers to the use of certain contraceptive methods by women and girls to prevent pregnancy after unprotected sexual intercourse. These methods include specific dedicated products (such as the brands Postinor 2 and Pregnon) and higher doses of other hormonal birth control pills (known as the Yuzpe method). EC is recommended for women who have had unprotected sexual intercourse and desire to prevent pregnancy. In Kenya, dedicated EC pills (ECPs), are available in the public family planning clinics and as part of post-rape care services; they are also widely found in Kenya's private sector pharmacies and clinics.

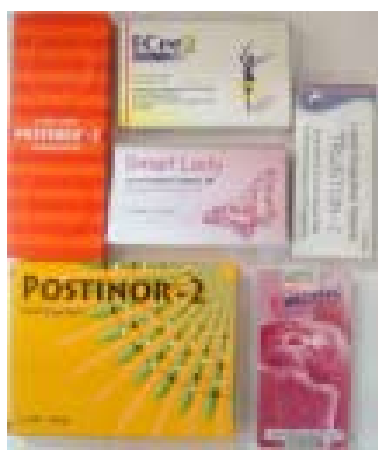

\section{Population Council}
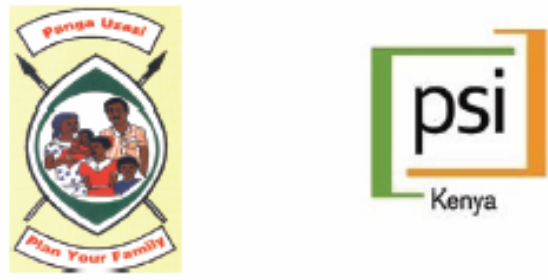


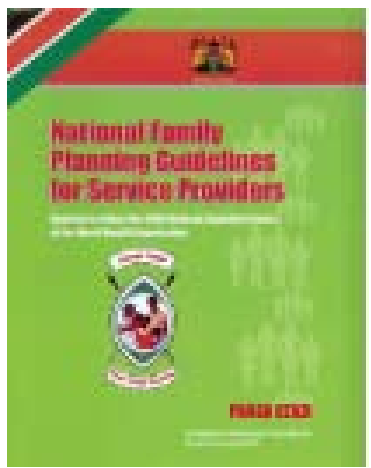

The Kenyan National Family Planning Guidelines recommend use of ECPs within 120 hours for women who have had unprotected sexual intercourse and desire to prevent pregnancy. ${ }^{2} \mathrm{EC}$ is the only contraceptive method that provides women with a second chance for preventing pregnancy after unprotected sex. ECPs do not cause abortion or harm an existing pregnancy, and are widely recognized as safe and easy to use. Any woman of reproductive age can use ECPs. While most women do not experience side effects, the most common side effects, including nausea, vomiting, and headaches, usually disappear within 24 hours. ECPs work by either inhibiting or delaying ovulation or preventing fertilization, depending on the time it is taken during the cycle. Dedicated ECPs are effective in preventing up to $95 \%$ of pregnancies, and the Yuzpe method is effective in approximately $75-80 \%$ of cases; the efficacy of ECPs is greater if taken as soon as possible after unprotected sex.

Visit the following websites for more information on EC:

- ECafrique: The African Forum on Emergency Contraception; www.ecafrique.org

- The International Consortium on Emergency Contraception; www.emergencycontraception.org

- Not-2-late.com http://ec.princeton.edu/

- The Latin American Consortium on Emergency Contraception (in Spanish); www.clae.info

\section{The initiative to mainstream ECPs in Kenya}

In 2006, the Population Council and PSI launched an initiative to support the MOPHS' efforts to strengthen ECP provision in the public and private sectors. Activities included a national awareness-raising campaign, technical assistance to the Division of Reproductive Health (DRH) to build capacity and ensure supply sustainability, and efforts to improve ECP services in private sector pharmacies.

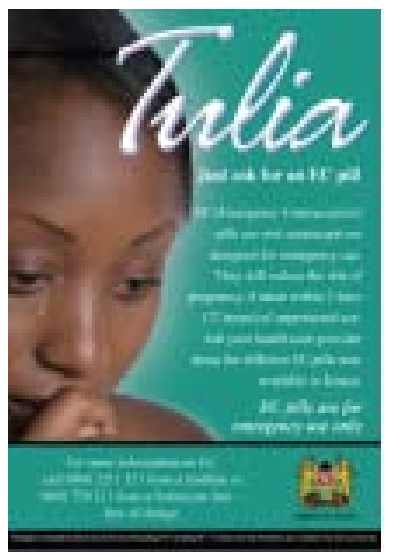

Awareness-raising campaign: A national mass-media campaign, branded Tulia ("relax" in Kiswahili) was undertaken to increase public awareness of ECPs. It included national and local-language radio spots, informational articles in print media, expert interviews on radio and TV, and EC messages presented through popular local soap operas. PSI also developed brochures answering clients' key questions and concerns regarding ECP use, which were distributed through pharmacies and private clinics.

To encourage bridging clients from ECPs to regular family planning methods, PSI organized community-level events, such as discussion groups and career fairs, that provided women aged 18-30 with information on ECPs and other regular family planning methods. All Tulia materials contained contact information for a youth reproductive health (RH) hotline run by Liverpool VCT, Care and Treatment. All hotline staff were trained to provide information and counseling to women with questions about EC.

Public sector capacity-building: A study carried out by the Population Council in 2007 found that, while $96 \%$ of FP providers had heard of EC, only $56 \%$ had ever been trained to provide ECPs and far fewer demonstrated adequate knowledge of the method. Guided by these findings, the DRH increased efforts to train FP providers on ECPs through contraceptive technology updates. Partners from the USAID-funded national AIDS, Population and Health Integrated Assistance (APHIA II) Project, which reaches providers across the country, were also encouraged to emphasize the method in their trainings. Through these efforts, over 2,000 providers received in-service training on ECPs between 2007 and 2008. A

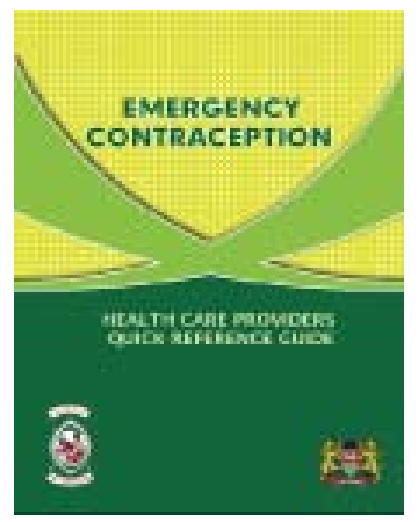


quick reference guide and job aid were also developed for providers, and the 2010 revision of the National Family Planning Guidelines includes significantly strengthened guidance on ECPs.

The government also took steps to strengthen pre-service training as a sustainable and costeffective approach to improving provider competence. With technical assistance from the Population Council, the Nursing Council of Kenya revised its syllabus to include training on ECPs for student nurses. Efforts are currently underway to integrate EC into the Kenya Medical Training College's curriculum.

Supply sustainability: To improve recordkeeping and allow facilities to re-order ECPs, in 2008 the DRH added a column for ECPs to the revised FP register. The MOPHS also included purchase of ECPs in its budget, and in 2009, procured 5,875,000 ECPs with its own funding.

Strengthened pharmacy services: The Population Council worked in collaboration with the Pharmaceutical Society of Kenya to address concerns of private providers regarding EC provision, and test strategies for improving ECP services in the pharmacies. The Council conducted an intervention study which worked to enhance the capacity of private pharmacy providers to provide quality ECP services. The study was conducted in 20 Nairobi pharmacies and included three components: detailing providers on the appropriate use of ECPs and how best to dispense ECP to clients, ensuring the availability of Tulia brochures and posters in participating pharmacies, and providing "cheat sheets" containing five simple messages on ECPs to display at the counter. The intervention also aimed to limit repeat use by "bridging" current users to other RH services, including VCT and longer-term FP.
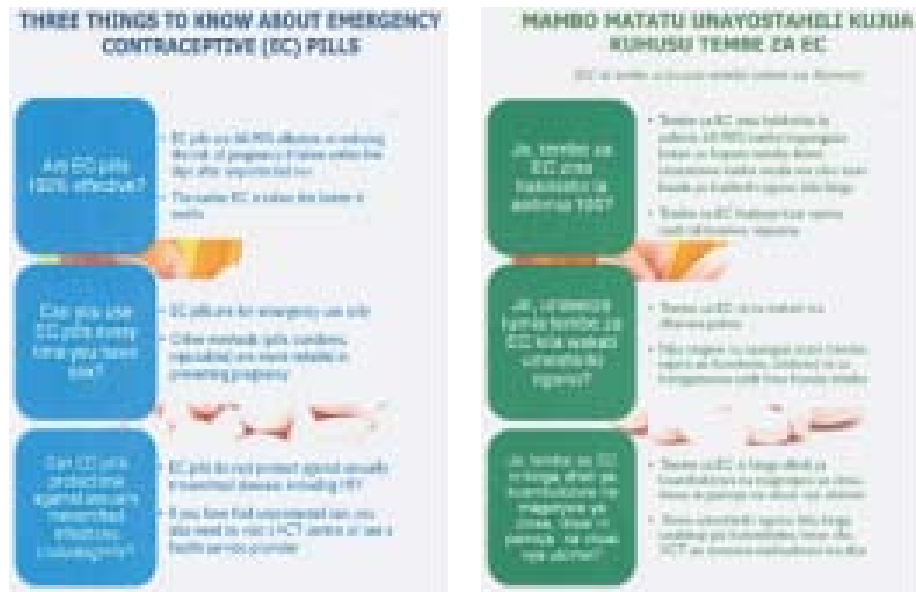

"Cheat" sheets with the key messages on EC (English and Kiswahili versions)

\section{Lessons learned on ECP provision in Kenya}

The initiative has helped improve understanding of the dynamics of ECP provision in Kenya, increased access to the method in the public and private sectors, and developed innovative and cost-effective strategies for providing basic information to users. The key lessons learned are summarized below.

\section{Awareness and use of ECPs has increased dramatically in Kenya, but still remains low}

Awareness and reported use of ECP increased dramatically over the life of the initiative. In 2003, the KDHS indicated that less than one quarter of Kenyan women had ever heard of ECPs. ${ }^{3}$ In 2007, PSI conducted baseline research in 13 major towns and peri-urban areas across seven provinces, and found similar patterns, with only $21 \%$ of women reporting having ever heard of ECPs. Of those, only 15\% could correctly identify ECPs as a contraceptive method taken after sex to prevent preg-

\begin{tabular}{|l|c|c|c|}
\hline Source & Year & $\begin{array}{c}\text { Ever heard of } \\
\text { EC (women) }\end{array}$ & $\begin{array}{c}\text { Ever } \\
\text { use }\end{array}$ \\
\hline DHS & 2003 & $24 \%$ & $0.9 \%$ \\
\hline PSI baseline $(n=675)$ & 2007 & $24 \%$ & $5 \%$ \\
\hline PSI endline $(n=1252)$ & 2009 & $56 \% *$ & $10 \% *$ \\
\hline
\end{tabular}

Table I: Knowledge and use of EC in Kenya, DHS and PSI baseline surveys 
nancy. ${ }^{4}$ By $2009,56 \%$ of women in the same sites had ever heard of ECP and $10 \%$ had ever used the method. ${ }^{5}$

ECP sales data, obtained from the major ECP distributors in Kenya, also demonstrate an increased demand for the method. Figure 1 charts the dramatic growth in ECP sales by distributors over a 22-month period. During that time, the number of ECP brands on the market increased from 3 to 4 , indicating a robust demand for the method. Similar trends are seen in the public sector, although the volumes are significantly lower. ${ }^{6}$

However, PSI's end line survey indicates that $44 \%$ of all eligible women are still not aware that ECP exists, and misconceptions are rife among those who do know about the method. Of all women who know of ECPs, one-third be-

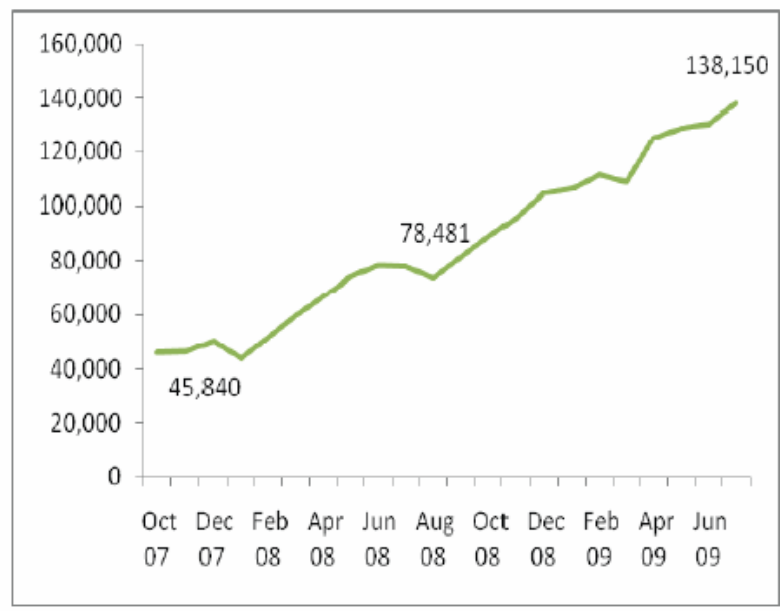

Figure I: National sales of 4 ECP brands, over project life lieve that it causes abortion, and only about two-thirds know the correct timeframe for using the method. This indicates the need for continued education and awareness-creation on ECPs.

\section{Private sector pharmacies dominate ECP provision in Kenya}

Data collected under the initiative demonstrate that private sector pharmacies are the most common access point for ECPs. PSI's 2007 baseline survey found that 94\% of women who had used ECP in the past two years obtained it from pharmacies. ${ }^{7}$ In 2009, their endline survey found that while $83 \%$ identified pharmacies as a place to obtain ECPs, only $25 \%$ mentioned government clinics. ${ }^{8}$

In 2008, as indicated in Figure 2, nationallevel ECP distribution through private sector pharmacies was approximately twice that distributed through the public sector.

Within government clinics, a 2007 record review found that $93 \%$ of the ECPs distributed in the previous 18 months were for sexual assault cases. While efforts under this initiative worked to strengthen ECP provision within FP and ARH services, it is likely that a bias toward sexual assault provision still exists within many public

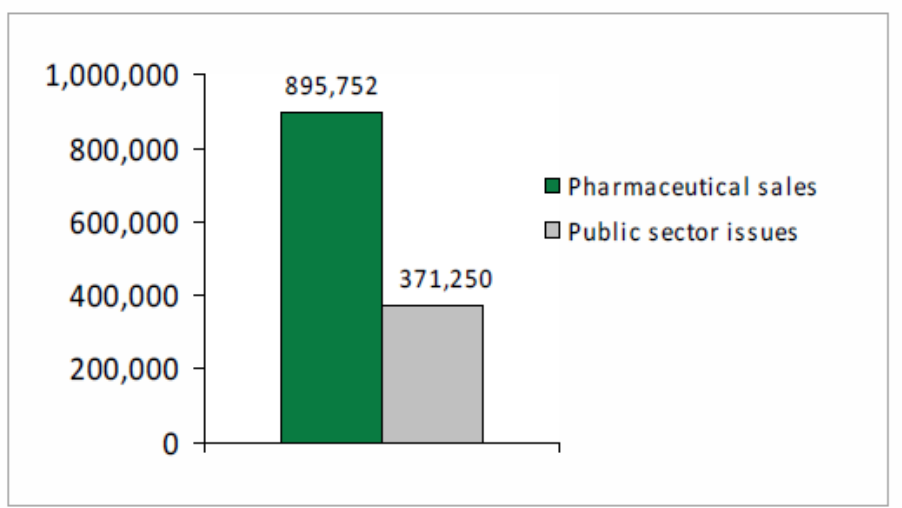

Figure 2: National sales of ECPs vs. public sector issues, 2008 health facilities. ${ }^{9}$

Qualitative research conducted with ECP users indicated that they preferred to access ECPs through pharmacies because it was convenient, quick and confidential. ${ }^{10}$ Two-thirds of women who purchased ECPs indicated that they had visited more than one pharmacy in an effort to maintain anonymity. ${ }^{11}$

These findings suggest that the challenge in delivering quality ECP services within pharmacies lies with balancing efforts to provide basic information on the method without compromising the qualities that make pharmacies so attractive to clients. Within the public sector, the challenge rests with increasing the speed and confidentiality of ECP services within the context of larger FP programs. 


\section{The majority of women who purchase ECPs from pharmacies are educated and employed}

Media reports have characterized ECP users, especially those who access EC from pharmacies, as "girls as young as 14."12 Research conducted under this initiative, however, indicates that this is not the case. In 2007, the Population Council conducted a client intercept study (where clients are interviewed after receiving a service) with 147 women who bought ECPs at pharmacies in urban pharmacies located in five provinces (Nairobi, Coast, Rift Valley, Nyanza, and Western).

The results show that the average age of women surveyed was 25 years, and the majority were between 20-29 years (72\%). None of these women reported that they were aged 14 or below, and only $11 \%$ of respondents were between the ages of 15-19. Most clients had a college/ university level of education (61\%) and 61\% were currently employed (including self-employment). About two-thirds $(65 \%)$ were either married/cohabiting or single but in a steady relationship, but most women $(57 \%)$ also reported engaging in sex on an infrequent or irregular basis. A significant proportion $(41 \%)$ reported having at least one child. ${ }^{13}$

\section{Some Kenyan women have used ECPs more than once in a month, but repeat users are less informed about the method}

Respondents in the 2007 client intercept study were asked about the number of times they had used ECPs in the past six months, frequency of use in relation to sexual activity, and time since last purchase of ECPs. The categorization of "repeat use" is based on the last question, and is defined as a client who has bought ECPs at least once previously in the past one month.

Data indicate that a majority (58\%) of women who had purchased ECPs had done so two or more times in the last month. Most of these purchasers (74\%) stated that they used ECPs as their only method during their last act of sex, and nearly as many (70\%) thought that ECPs were more convenient than other methods, while almost half preferred ECPs over methods such as daily contraceptive pills or injectables.

While repeat use of ECPs may be a conscious decision, it is not necessarily an informed one. The data also demonstrate that women who repeatedly used ECPs had greater misperceptions about the method's mechanism of action and efficacy. Nearly 60 percent believed that ECPs are $100 \%$ effective, and many incorrectly believed that it would cause infertility or abortion. Overconfidence in ECP's efficacy is likely to be one factor underpinning repeat use, with the benefits of convenience in the short-term outweighing perceived long-term consequences. ${ }^{14}$

It is important to note that no significant negative health consequences have been associated with repeat use of ECP. ${ }^{15}$ Current national and international guidelines, however, do not encourage reliance on EC as a regular method of FP. According to the World Health Organization, recurrent use of EC indicates the need for further counseling on contraceptive options. ${ }^{16}$ No conclusive evidence is available on the efficacy of ECPs if taken more than once in a cycle.

\section{Pharmacies can provide better ECP services with minimal investment}

Given the key role pharmacies currently occupy in the provision of ECP in Kenya, and the demonstrated need for better client counseling, innovative efforts are needed to improve EC services within pharmacies.

The strategy for providing basic information to pharmacy clients tested under this initiative demonstrated promising results. Results of this intervention indicated that, when given basic information, pharmacy staff were more likely to provide basic information on ECPs (including when and how to use, mechanism of action, side effects, and efficacy) and discuss other FP and RH services with clients. These results suggest that sales staff at private sector pharmacies can deliver better ECP services, if given the proper tools. It also indicates that extensive, and often costly, training efforts are not needed to improve services within pharmacies. ${ }^{17}$ 


\section{Integrating skills and knowledge on ECPs into existing pre-service and in-service training programs can enhance public sector provision}

Under the initiative, efforts focused on integrating EC into existing pre- and in-service training programs in a cost-effective and sustainable manner. With minimal resources, modules on ECPs were inserted into ongoing trainings conducted by APHIA II partners and in the regular MOPHS Contraceptive Technology Updates (CTUs); evaluation data showed increased knowledge among trained providers. Perhaps the most strategic investment was in pre-service training, where limited technical and financial support enabled the integration of EC into the revised Nursing Council's curriculum, ensuring that all future nurses will receive instruction on ECPs.

These experiences demonstrate that existing FP and RH initiatives can be successfully used to promote knowledge on ECPs. They also underscore the utility of integrating EC into existing activities, which is more-cost effective than stand-alone trainings and promotes the principle that EC should be addressed in the context of comprehensive FP and post-rape care services.

\section{Active advocacy is necessary to ensure adequate ECP stocks in the public sector.}

Supply sustainability of all contraceptives, especially ECPs, remains a major challenge for the Kenyan government. Continued or sustained stock-outs would undermine the gains made during this initiative, and limit the impact of the policy and program changes that have been undertaken in recent years. As knowledge of ECPs increase throughout the country, so will supply requirements, and efforts to ensure sufficient commodities should continue.

Under the leadership of the DRH, advocacy efforts ensured that ECPs were included in the national contraceptive security plan and subsequent procurements. Since 2005, UNFPA has donated approximately 1,100,000 units to the MOPHS. In 2009, the MOPHS committed its own funds to purchase the country's largest procurement of ECPs to date of 5,875,000 units.

\section{Recommendations}

The following recommendations are based on the lessons learned under this initiative.

1. Efforts to create public awvareness and correct knowledge of ECPs should be continued. While knowledge of ECPs is increasing in Kenya, many potential beneficiaries are still unaware of the method and many others are misinformed. Accurate public information and education is critical for encouraging correct use of ECPs. It is important, therefore, to include messages on ECPs in comprehensive FP communication campaigns. This can be achieved by integrating the existing Tulia materials and messages into the national RH communication strategy operational plan, and in the DRH's community education and communication activities. The media can also play a critical role in creating correct public perceptions of the method, and should be regarded as a partner in these activities.

2. Professional associations, including the Pharmaceutical Society of Kenya and the Kenya Pharmaceutical Association, should continue educating their members on proper ECP provision. Given the central role pharmacies play in ECP access in Kenya, professional associations should work to confirm that their members are aware of strategies for ensuring clients are provided with the information they need to make informed decisions on ECP use. Such strategies need not be costly or time-intensive; this initiative demonstrated one model for increasing information provision in pharmacies, and others are likely to be feasible. At a minimum, the professional associations should include informational sessions and discussions on ECPs at all general meetings. 
3. All MOPHS training partners should ensure that ECPs are integrated into all trainings on FP, RH, adolescent health, or post-rape care. Numerous local and international NGOs assist the MOPHS with provider training. These partners' contributions can also be used to increase knowledge on ECPs, with as little as two additional hours of instruction for trained health care providers. The DRH should integrate existing training materials and job aids into a standardized module on ECPs to ensure that all partners offer uniform, high-quality instruction.

4. All pre-service training institutions and bodies should include ECP provision in their curricula and examinations. Pre-service training is necessary to ensure that the next generation of Kenya's health professionals are well equipped to provide this important and increasingly popular method. To do this, the country's leading medical pre-service training institutions must revise their curricula to reflect the MOPHS' renewed emphasis on quality ECP provision.

5. The MOPHS, donors, and partners should continue to ensure that adequate ECP supplies are available in the public sector. Adequate stocks are essential in ensuring the success of public sector ECP provision. Remarkable progress toward this has been achieved through the inclusion of ECP in the government's FP commodities procurement and security plans. It is recommended that donors and other MOPHS partners continue to support the government to ensure that this emphasis on stock sustainability is maintained. Donors can also encourage their partners to integrate ECP issues in their reproductive health communications, service delivery, logistics, trainings, and research programs, and to explore innovative ways to strengthen private sector provision.

\section{Conclusion}

Kenya has emerged as a leader in EC programming in the region. Through this initiative, it has demonstrated that it is possible to strengthen ECP services in both the public and private sectors while at the same time increasing public awareness, knowledge, and use of the method.

The Kenyan experience can serve as a model for other countries on the continent interested in mainstreaming ECP services. While Kenya may have a longer history with the method than other African countries, ECPs are rapidly becoming widely available in African pharmacies due to the aggressive expansion of new products. Countries such as Uganda, Botswana, Ghana, Nigeria, Malawi, and Senegal are beginning to grapple with increased access in the private sectors, while many other governments are now more widely providing ECPs as a core element of post-rape care. The lessons learned from Kenya can serve as an invaluable resource to these countries.

\section{References}

1. Population Services International- Kenya. Mainstreaming Emergency Contraception in Kenya: Final Narrative Report. October 2009. Unpublished report.

2. Kenya Ministry of Public Health and Sanitation, Division of Reproductive Health. National Family Planning Guidelines for Service Providers. 2010 Revision. Nairobi: Kenya.

3. Central Bureau of Statistics (CBS) et al. Kenya Demographic and Health Survey 2003. 2004. Calverton, MD: CBS et al.

4. Population Services International-Kenya. TRaC Summary Report: Baseline Study on EC Use among Urban and Peri-Urban Kenyan Women. 2007. Unpublished report.

5. Population Services International- Kenya. Mainstreaming Emergency Contraception in Kenya: Final Narrative Report. October 2009. Unpublished report.

6. Keesbury J, Liambila et al. Mainstreaming Emergency Contraception in Kenya : Final Project Report. 2009. Population Council: Nairobi. 
7. Population Services International-Kenya. TRaC Summary Report: Baseline Study on EC Use among Urban and Peri-Urban Kenyan Women. 2007. Unpublished report.

8. Population Services International- Kenya. Mainstreaming Emergency Contraception in Kenya: Final Narrative Report. October 2009. Unpublished report.

9. Keesbury J, Owino B, and Bradford S. Emergency Contraception, Female Condoms and IUDs in Kenya's Public Sector: Findings from a National Diagnostic Assessment. 2007. Population Council: Nairobi.

10. Population Services International-Kenya. TRaC Summary Report: Baseline Study on EC Use among Urban and Peri-Urban Kenyan Women. 2007. Unpublished report.

11. Benter Owino and Jill Keesbury. Who Uses Emergency Contraceptives? A Profile of EC Users from Urban pharmacies in Kenya. 2007. Population Council: Nairobi.

12. Wesangula D. Scandal of birth pills for teenagers. Daily Nation, Nairobi: Kenya; 7 September 2008; 5-6.

13. Keesbury J, Morgan G, Owino B. Is repeat use of emergency contraception common among pharmacy clients? Evidence from Kenya. Manuscript under review.

14. Keesbury J, Morgan G, Owino B. Is repeat use of emergency contraception common among pharmacy clients? Evidence from Kenya. Manuscript under review.

15. United Nations Development Program/ United Nations Population Fund/ World Health Organization/ World Bank Special Programme on Research, Development and Research Training on Human Reproduction. Task Force on Post-Ovulatory Methods of Fertility Regulation. Efficacy and side effects of immediate postcoital levonorgestrel used repeatedly for contraception. Contraception 2000; 61:303-8.

16. World Health Organization. Medical Eligibility Criteria for Contraceptive Use, Third edition. Geneva: World Health Organization, 2004.

17. Obare F, Keesbury J, Liambila W. 2009. Bridging users of emergency contraceptives to other family planing and reproductive health services through private sector pharmacies in Nairobi, Kenya. Population Council: Nairobi.

This brief was prepared by Jill Keesbury, Monica Wanjiru, and Katherine Maina. Please contact ecafrique@popcouncil.org for more information. 


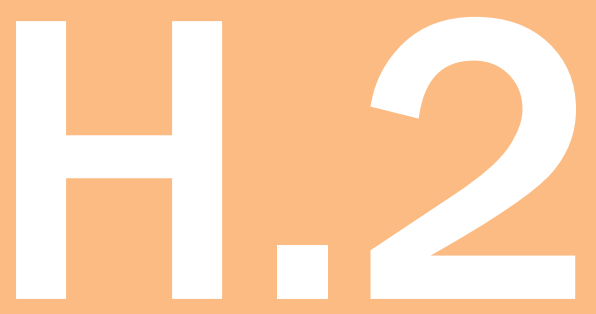

$$
\begin{aligned}
& \text { HEALTH CARE } \\
& \text { PROVIDERS } \\
& \text { QUICK } \\
& \text { REFERENCE } \\
& \text { GUIDE }
\end{aligned}
$$




\section{Emergency Contraception Health Care Providers Quick Reference Guide}

\section{Introduction}

According to the Kenya Demographic and Health Survey of 2003, close to half of the births in the preceding five years were mistimed or unwanted. Unplanned pregnancies lead women to seek abortions or have children they do not care for effectively. Use of emergency contraceptives $(E C)$ is recommended for women who have had unprotected sexual intercourse and want to prevent pregnancy. The Ministry of Health recommends use of emergency contraceptives (EC) within 120 hours for women who have had unprotected sexual intercourse and want to prevent pregnancy. Effective provision of EC is an important component of adolescent reproductive health and post-rape care programs.

"I think we have not adequately explained to the community that the morning-after pill should be used only in situations where people have accidentally had unprotected sex or in the case of sexual coercion." (Dr. Shahnaaz Sharif, Head of Technical Services, Ministry of Public Health \& Sanitation. Remarks made at the World Contraception Day event at Kangemi, Nairobi on 26 September 2008.)

"We need to educate members of the public so that they have the correct information regarding the use of the morning-after pill." (Rosalyn Gichora, District Officer, Nairobi West District. Remarks made at the World Contraception Day event at Kangemi, Nairobi on 26 September 2008)

\section{Why This Guide?}

The Health Care Providers Quick Reference Guide has been developed as part of a larger ongoing program on mainstreaming EC in the public and private sectors. The main objective of this guide is to give an opportunity to health care providers to be able to make quick reference on any key issue with regard to EC in the course of their work. It is intended to supplement the information on EC provided in the current $\mathrm{MOH}$ Family Planning Guidelines for Service Providers.

\section{What Is EC?}

Emergency contraception refers to the use of certain contraceptive methods by women and girls to prevent pregnancy after unprotected sexual intercourse. These methods include specific products like Postinor 2, and normal birth control pills. They should not be used as routine methods of family planning (FP).

\section{Why Is EC Important?}

- EC provides a second chance for preventing pregnancy after unprotected sex.

- EC can reduce unwanted pregnancy which may result in child neglect, abandonment, and unsafe abortions. Unsafe abortion is a major cause of maternal death in Kenya.

- EC is an important element in adolescent reproductive health programs. Young people need to have correct information on many of the risk factors that are likely to negatively impact their lives such as sexually transmitted infections (STIs) HIV/AIDS and unintended pregnancies.

- EC is important for post-rape care, prevention of mother to child transmission of HIV, and is an essential component of quality FP service provision.

\section{When Does a Woman Need to Use EC?}

EC is used after unprotected sex, including in the following situations:

- When no FP method is used.

- When a method is used but it does not function properl,y e.g., condom breaks, IUD slips out.

- When a woman forgets to take oral contraceptive pills for two or more days, or delays injectable for more than two weeks

-When a woman is raped/coerced into unprotected sex.

\section{Key Points about EC Pills}

- Safe, effective, and easy to use. EC can be used safely by adolescents. 
- Should be started as soon as possible, but within 120 hours of unprotected sex. The second pill should be taken within 12 hours after the first or alternatively the two pills can be taken at once (as a single dose).

- Referred to as "morning-after pill", but this reference is misleading as it implies that one has to wait for some time before using the pill.

- No medical exam or pregnancy tests necessary.

- Can be used any time of the menstrual cycle.

- Should not be used as a regular method of contraception because EC pills are less effective and have more side effects than other family planning methods.

- EC pills do not work once a woman is pregnant. Therefore women/girls who are already pregnant should not take EC pills. However they will not harm a fetus that is already formed or cause a miscarriage.

- EC pills are available in $\mathrm{MOH}$ facilities and over the counter at pharmacies.

\section{How Does EC Prevent Pregnancy?}

EC pills work in various ways depending on the time in a woman's cycle when she has sexual intercourse. EC does not cause abortion because it works before implantation.

EC Pills are thought to:

- Inhibit or delay ovulation.

- Inhibit/slow down transportation of egg/sperm through the fallopian tubes, hence preventing fertilization.

- Prevent implantation.

\section{Types of Hormonal EC Pills/ Characteristics of EC Pills}

1. Dedicated EC pills contain the same progestin hormones as other progestin-only pills, although in higher doses. They are more effective than combined oral contraceptive pills and cause fewer side effects. This regimen prevents pregnancy by about $85 \%$ if taken within 120 hours.

- There are many brands of dedicated EC pills currently available in Kenya, such as Postinor 2, Pregnon, Smart Lady, ECee2, and Truston2.

- Some of these brands are found in government health facilities and should be ordered in the same way as other contraceptives.
2. Combined oral contraceptive pills, also called Yuzpe method, contain the hormones estrogen and progestin and prevent about $75 \%$ of expected pregnancies.

3. Progestin-only contraceptive pills can be used for EC. One needs two doses of 20 tablets.

\section{The following are dosage guidelines for different EC pills regimens}

\begin{tabular}{|c|c|c|c|c|}
\hline Pill type & $\begin{array}{l}\text { Common } \\
\text { brand } \\
\text { names }\end{array}$ & $\begin{array}{l}\text { Tablets } \\
\text { per } \\
\text { dose }\end{array}$ & Doses & $\begin{array}{l}\text { Timing of } \\
\text { administration }\end{array}$ \\
\hline $\begin{array}{l}\text { Dedicated EC pill- } \\
\text { LNG ECP package } \\
\text { with single dosage } \\
\text { pill of } 1.5 \mathrm{mg} \text { of } \\
\text { levonorgestrel }{ }^{* *}\end{array}$ & $\begin{array}{l}\text { Postinor } 2 \\
\text { Pregnon } \\
\text { Smart lady } \\
\text { Ecee2 }\end{array}$ & $\begin{array}{l}1 \\
1 \\
1 \\
1\end{array}$ & $\begin{array}{l}1 \\
1 \\
1\end{array}$ & $\begin{array}{l}\text { Dose to be } \\
\text { taken within } \\
120 \text { hours after } \\
\text { unprotected } \\
\text { sex. }\end{array}$ \\
\hline $\begin{array}{l}\text { Dedicated EC pills- } \\
\text { LNG ECP package } \\
\text { containing two pills } \\
\text { of } 0.75 \mathrm{mg} \text { of lev- } \\
\text { onorgestrel each }\end{array}$ & $\begin{array}{l}\text { Postinor } 2 \\
\text { Pregnon } \\
\text { Smart lady } \\
\text { Ecee2 }\end{array}$ & $\begin{array}{l}2 \\
2 \\
2 \\
2\end{array}$ & $\begin{array}{l}1 \\
1 \\
1 \\
1\end{array}$ & $\begin{array}{l}\text { Dose to be } \\
\text { taken within } \\
120 \text { hours after } \\
\text { unprotected } \\
\text { sex. }\end{array}$ \\
\hline $\begin{array}{l}50 \text { mcg estrogen } \\
\text { pills }\end{array}$ & Eugynon & 2 & 2 & \multirow{3}{*}{$\begin{array}{l}\text { First dose to be } \\
\text { taken within } 120 \\
\text { hours after un- } \\
\text { protected sex. } \\
\text { Second dose } 12 \\
\text { hours later. }\end{array}$} \\
\hline $\begin{array}{l}30 \text { mcg estrogen } \\
\text { pills }\end{array}$ & $\begin{array}{l}\text { Micro- } \\
\text { gynon }\end{array}$ & 4 & 2 & \\
\hline Progestin only pills & Microlut & 20 & 2 & \\
\hline
\end{tabular}

** $1.5 \mathrm{mg}$ of levonorgestrel or two $0.75 \mathrm{mg}$ of levonorgestrel pills taken at once in a single dose improves compliance (1.Dada OA, Godfrey EM, Piaggio G, von Hertzen $\mathrm{H}$. "A randomized, double-blind, noninferiority study to compare two regimens of levonorgestrel for emergency contraception in Nigeria." Contraception 2010; 82(4): 373-8. 2. Piaggio G, Kapp N, von Hertzen H. "Effect on pregnancy rates of the delay in the administration of levonorgestrel for emergency contraception: a combined analysis of four WHO trials." Contraception 2011; 84 (1): 35-9).

\section{Side Effects and Management}

- Nausea and vomiting are the most common side effects.

- Other possible effects include headaches, dizziness, fatigue, and breast tenderness due to the high hormone doses in emergency contraception pills.

- Most side effects generally disappear within 24 hours of taking the pills.

- To reduce the effects of nausea, EC pills can be taken with food or a medical provider can offer anti-nausea drugs before taking EC.

- If a woman vomits $<2$ hours after taking a dose of EC the dose should be repeated.

- If vomiting occurs more than 2 hours after taking ECPs, she does not need to take any extra pills. 


\section{Counseling Clients}

Women needing EC may be in crisis and fear unplanned pregnancy. As much as possible it is important for a provider to counsel a client on EC. Unless in the case of rape, it is an opportunity to discuss use of regular FP method.

- Recommend that the client use a method of FP for the rest of the cycle after taking EC pills.

- Many women who need EC also need protection from STIs/HIV. Counseling on EC is an opportunity to discuss the risks of STIs and prevention options.

-When you explain mode of action to clients, reassure them that EC pills do not cause abortion.

- Discuss the possibility that EC may fail.

- Refer clients for FP and other reproductive health services. Women who have been raped or traumatized need to be referred for more comprehensive medical and psychosocial care.

\section{Starting Family Planning Methods after EC}

\begin{tabular}{|l|l|}
\hline Method & When to start \\
\hline Condom & $\begin{array}{l}\text { Immediately after EC } \\
\text { Use also for dual protection }\end{array}$ \\
\hline Oral contraceptive pills & $\begin{array}{l}\text { Next day after 2nd dose of EC } \\
\text { or 1-7 days after menses }\end{array}$ \\
\hline $\begin{array}{l}\text { Injection } \\
\text { IUD } \\
\text { Norplant }\end{array}$ & $1-7$ days after next period \\
\hline
\end{tabular}

\section{EC pills and HIV/AIDs/STIs}

EC pills do not protect against STIs including HIV.

- All EC users should also be referred for voluntary counseling and testing.

- In case of rape, providers can give post-exposure prophylaxis for STIs/HIV.

\section{Common questions}

-What are the effects of EC on periods?

EC pills do not cause periods to start immediately. Periods will come at the normal time but may be delayed or come early by $2-3$ days.

- Can EC pills protect one for the rest of the cycle? It will not, and any further unprotected acts put one at risk. Women should use a regular method of FP or condoms for further protection.

\section{- Can EC pills harm an already formed baby?}

No. It has been determined that EC pills do not have any serious harmful effects ona formed baby.

-When can one resume/start a regular FP method after taking EC?

One can start by using condoms and pills. One has to wait until the next period to begin using injections, IUDs and implants.

- Can I use EC pills every time I have sex?

Women/girls should not use EC pills as a regular method. They should only be used in emergency situations. EC pills are less effective than many regular FP methods.

\section{-What if I have unprotected sex again after taking EC?}

If one has unprotected sex after using EC, it will not offer protection from pregnancy. One will need to repeat the treatment, unless already using a regular FP method.

\section{-What if I had sex multiple times before taking EC pills?}

You can still use EC pills if the last time you had sex was within five days. If one is already pregnant from an earlier act of unprotected sex, the EC pills will not have any effect.

This booklet has been adapted from the National FP Guidelines (Kenya MOH, 2005), with additional information drawn from Family Planning: A Global Handbook for Providers (WHO: Geneva, 2008). The adaptation was conducted by the staff of the Division of Reproductive Health, Ministry of Public Health and Sanitation and ECafrique staff of the Population Council. Publication date 2008. 


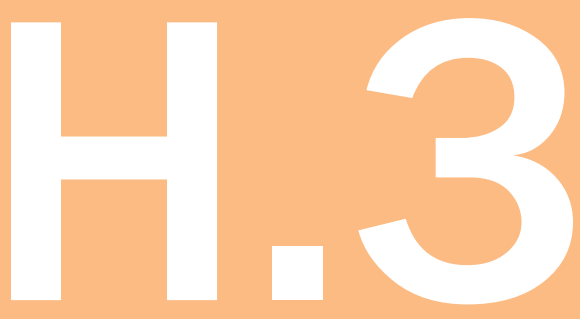

SELLING

PROTOCOL FOR

EMERGENCY

CONTRACEPTION

PILLS 
Below is a recommended emergency contraceptive pills (ECPs) selling protocol that the Population Council in collaboration with other professionals proposes can be used in dispensing the emergency pills.

\section{Assess the risk of pregnancy:}

- In case of missed pills: Advise the patient to carry on with the next pill as normal. If they had unprotected sex, then emergency contraceptive pills are indicated. Inform the patient that they will not be covered by the contraceptive and that a barrier form of contraception such as a condom should be used for a further 10 days or until the end of the cycle. They can have their normal break and carry on with the regular contraception as normal.

- In case of a broken, slipped condom, the emergency contraceptive pills (ECPs) are indicated and should be administered as soon as possible.

- In case of unprotected sex including both consensual and nonconsensual sex: EC pills are indicated and should be administered as soon as possible.

\section{Establish if the client is taking any other medication.}

Many enzyme-inducing drugs reduce the effectiveness of emergency pills. Drugs to watch out for are anticonvulsants such as carbamezapine, and phenytoin; anti-HIV drugs such as ritonavir; anti-TB drugs such as Rifampicin and Rifambutin; herbal drugs; cyclosporin; and antibiotics.

3. Establish if the client has any stomach condition such as Crohn's or severe liver disease. These can reduce the absorption and metabolism of ECPs.

4. Ensure that the client is within the 120 -hour period.

\section{Give advice:}

a. EC Pills: two tablets can be taken at the SAME time, avoiding the need to wait for 12 hours, with the same efficacy.

b. Take the pills as soon as possible. c. The pills may induce nausea; however, if the client vomits within three hours of taking the pill, she should return and purchase another dose as the first dose may not work.

d. Side effects are rare and transient. Side effects may be headaches, dizziness, breast tenderness, nausea, and vomiting. If the client is concerned, she should speak to her doctor; however, after years of research on this drug, there is no evidence of any longacting adverse effects.

e. Advise the client that her next period may be heavy or light, early or late. If it is more than five days late she should seek medical advice and get herself tested for pregnancy.

f. Advise clients on the use of regular contraception and risks of STIs.

6. EC reference materials should be given out. These include the EC Quick Reference Guide and the 2010 edition of the National Family Planning Guidelines by the Division of Reproductive Health (DRH) of Kenya's Ministries of Health for providers; and guides such as the Tulia patient information brochure developed by $\mathrm{MOHs}$ and partners for patients. The patient information guides should be given out to complement the advice given.

7. Communication: Communicate with empathy, discretion, and in a nonjudgmental way. Ask open questions and double-check the patient's understanding. If you can, have a quiet area in your pharmacy where private discussions can be held.

Some pharmacists and health care professionals have expressed concerns that women might "abuse" emergency contraception pills by using them repeatedly or using them instead of regular contraception. The main point to bear in mind here is that from a safety point of view, no serious side effects have been reported from repeated use of levonorgestrel ECPs, usually a change in the menstrual cycle is seen. If advice is given on regular contraception and the risk of STIs including HIV/AIDS at the point of supply of ECPs, then pharmacists will also be playing a major role in the effective use of emergency contraception and family planning in general. It is in the pharmacists' hands to uplift the profession. The sale and supply of ECPs enables pharmacists to play a more active role in improving the sexual health of the nation. 
$1-4$

JOB AID FOR

BRIDGING

EC USERS

TO OTHER

RH SERVICES 


\section{THREE THINGS TO KNOW ABOUT EMERGENCY CONTRACEPTIVE (EC) PILLS}

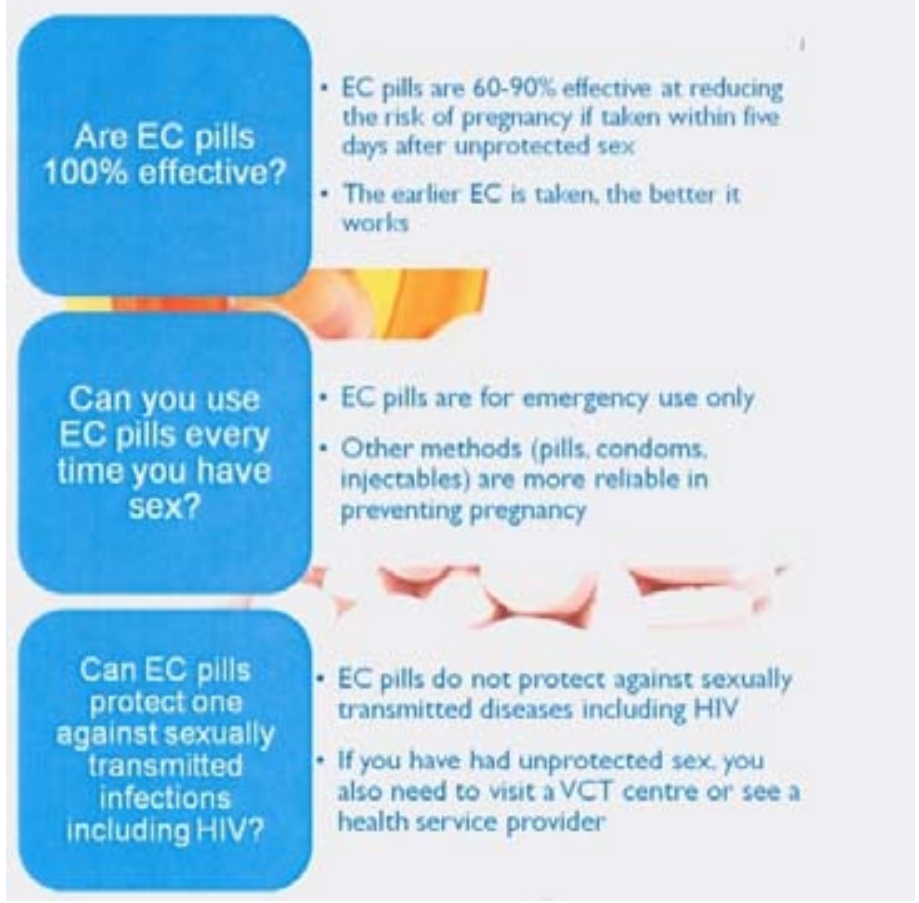

MAMBO MATATU UNAYOSTAHILI KUJUA KUHUSU TEMBE ZA EC

(EC ni tenbe an kuraia mimba makati ma dharuma)

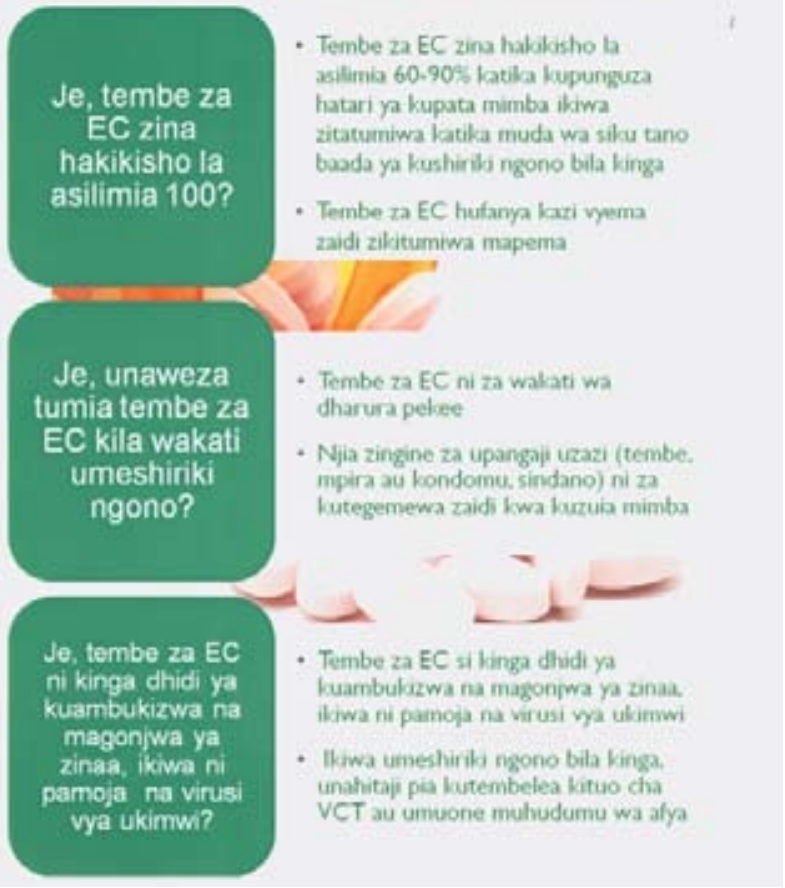

Source: MOH-Kenya. 2010. National Family Planning Guidelines for Services Providers. 


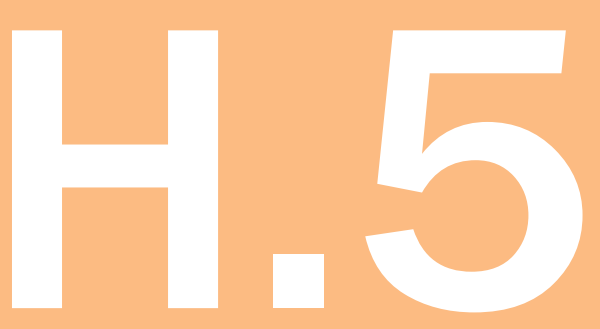

HORMONAL

EMERGENCY

CONTRACEPTION 


\section{HORMONAL EMERGENCY CONTRACEPTION: WHAT IS IT?}

Emergency contraception refers to the use of certain contraceptive methods by women in the reproductive age group to prevent pregnancy after unprotected sexual intercourse. Hormonal emergency contraceptive pills (ECPs) must be taken within 120 hours of intercourse, however, the sooner they are taken, the more effective they are. EC provides a second chance for preventing pregnancy after unprotected sex, either accidental or following coerced sex/rape.

\section{It should be emphasised that emergency contraception should not be used on a regular basis (from month to month) because it is less effective than other methods.}

Depending on the regimen used and number of hours passed since unprotected intercourse, emergency contraceptive pills seem to prevent between $75 \%$ and $95 \%$ of pregnancies that would otherwise have occurred. The average chance of pregnancy resulting from one act of unprotected intercourse in the second or third week of the menstrual cycle is estimated at $8 \%$; after emergency oral contraception it is $1-2 \%$. The sooner after unprotected intercourse ECPs are used, the more effective they are in preventing pregnancy. Also a progestin-only regimen is more effective than a combined oral contraceptives regimen.

Emergency contraception pills work in various ways to prevent pregnancy. This depends on the time in a woman's cycle when she has sexual intercourse. EC does not cause abortion because it works before implantation. Thus EC pills prevent pregnancy by:

- Preventing or delaying ovulation; and

- Inhibiting or slowing down transportation of the egg and/or sperm through the fallopian tubes; hence preventing fertilization and implantation.

\section{TYPES OF HORMONAL EC PILLS AND DOSAGE}

Combined Oral Contraceptives (COC) (also called Yuzpe method).

These contain the hormones estrogen and progestin and prevent about $75 \%$ of the expected pregnancies.

50 mcg estrogen pills (e.g. , Eugynon): Two tablets to be taken as soon as possible, but within 120 hours of unprotected intercourse. Repeat same dose in 12 hours. A total of 4 pills are required.

Or

30 mcg estrogen pills (e.g., Microgynon): Four tablets to be taken as soon as possible, but within 120 hours of unprotected intercourse. Repeat same dose in 12 hours. A total of 8 pills are required.

\section{Progestin-only Oral Contraceptives}

\section{Dedicated emergency contraceptive (levonogestrel) pills:}

These contain the same progestin hormones as other progestin-only pills, although in higher doses. They are more effective than combined pills. Examples of brands of dedicated EC pills available in Kenya are: Postinor 2, Pregnon, Smart lady, ECee2, and Truston2, among others.

One $\mathbf{7 5 0}$ mcg levonorgestrel pill to be taken as soon as possible, but within 120 hours of unprotected intercourse. Repeat same dose in 12 hours. A total of 2 pills are required.

Or

Two $\mathbf{7 5 0}$ mcg levonorgestrel pills to be taken as a single dose as soon as possible, but within 120 hours of unprotected intercourse. This regimen is preferred because the issue of compliance with treatment does not arise.

Or

Regular progestin-only pill (POP) may be used: 20 tablets taken within 120 hours of unprotected intercourse. Repeat same dose in 12 hours. A total of 40 pills are required. 
Dosage guidelines for different EC regimens

\begin{tabular}{|c|c|c|c|c|c|}
\hline PILL TYPE & $\begin{array}{l}\text { COMMON } \\
\text { BRANDS }\end{array}$ & $\begin{array}{l}\text { TABLETS } \\
\text { PER DOSE }\end{array}$ & DOSES & $\begin{array}{l}\text { TOTAL } \\
\text { DOSES }\end{array}$ & $\begin{array}{l}\text { TIMEFRAME FOR } \\
\text { ADMINISTRATION OF DOSAGE }\end{array}$ \\
\hline \multicolumn{6}{|c|}{ a) Combined oral contraceptive pills: } \\
\hline 50 mcg estrogen pills & Eugynon & 2 & 2 & 4 & \multirow{2}{*}{$\begin{array}{l}\text { First dose within } 120 \mathrm{hrs} ; 2^{\text {nd }} \\
\text { dose } 12 \text { hrs later }\end{array}$} \\
\hline $30 \mathrm{mcg}$ estrogen pills & Microgynon & 4 & 4 & 8 & \\
\hline \multicolumn{6}{|c|}{ b) Progestin-only dedicated EC Pills: } \\
\hline $\begin{array}{l}750 \text { mcg levonorg- } \\
\text { estrel pill }\end{array}$ & $\begin{array}{l}\text { Postinor 2, } \\
\text { Pregnon, } \\
\text { Smart lady, } \\
\text { Ecee2, } \\
\text { Truston2 }\end{array}$ & $\begin{array}{l}1 \\
1 \\
1 \\
1 \\
1\end{array}$ & $\begin{array}{l}2 \\
2 \\
2 \\
2 \\
2\end{array}$ & 2 & $\begin{array}{l}\text { First dose within } 120 \text { hrs after } \\
\text { unprotected sex; } 2^{\text {nd }} \text { dose } 12 \\
\text { hrs later }\end{array}$ \\
\hline $\begin{array}{l}1.5 \mathrm{mg}(1500 \mathrm{mcg}) \\
\text { levonorgestrel pill }^{\star}\end{array}$ & $\begin{array}{l}\text { Postinor 2, } \\
\text { Pregnon, } \\
\text { Smart lady, } \\
\text { Ecee2, } \\
\text { Truston2 }\end{array}$ & $\begin{array}{l}2 \\
2 \\
2 \\
2 \\
2\end{array}$ & $\begin{array}{l}1 \\
1 \\
1 \\
1 \\
1\end{array}$ & 2 & $\begin{array}{l}\text { Single dose within } 120 \mathrm{hrs} \\
\text { after unprotected sex. }\end{array}$ \\
\hline \multicolumn{6}{|c|}{ c) Regular progestin only pill (POP) } \\
\hline $\begin{array}{l}\text { Regular progestin- } \\
\text { only pill (POP) }\end{array}$ & Microlut & 20 & 2 & 40 & $\begin{array}{l}\text { First dose within } 120 \text { hrs after } \\
\text { unprotected sex; } 2^{\text {nd }} \text { dose } 12 \\
\text { hrs later }\end{array}$ \\
\hline
\end{tabular}

* This regimen is preferred since it improves compliance (WHO 2008: Global Handbook for Providers on FP and Emergency Contraception- Health Care Providers Quick reference Guide(MOPHS, DRH 2008).

\section{ADVANTAGES}

- Provides emergency protection (prevents pregnancy) in about $75 \%$ to $95 \%$ of those at risk.

- EC can reduce unwanted pregnancy which may result in child neglect, abandonment, or unsafe abortions which are a major cause of maternal death in Kenya.

- Is an important element in post-rape care, prevention of mother-to-child transmission of HIV and is an essential component of quality family planning service provision.

- Safe, effective, and easy to use.

- No medical examination or pregnancy tests are necessary or required.

- Can be used any time during the menstrual cycle.

- Emergency contraception pills are available in the government, private, and NGO health facilities and over the counter at pharmacies.

\section{LIMITATIONS}

- Only effective within 120 hours of unprotected intercourse.

- Not to be used as a regular method.

- Does not protect against STIs/HIV/AIDS.

- May cause nausea (more common for COC regimen). 


\section{WHO CAN USE EMERGENCY CONTRACEPTION ?}

Emergency oral contraception should not be used in place of regular family planning methods. It should be emphasised that EC contains a much higher dose of the hormones compared to the regular hormonal contraceptive methods. Therefore, it should be used only in an emergency, for example:

- Sex took place without contraception, and the woman wants to avoid pregnancy.

- A woman has run out of oral contraceptives, has missed 2 or more POPs, or is more than 4 weeks late for her DMPA injection and has had unprotected intercourse.

- A woman has had coerced sexual intercourse, such as rape.

- A condom has broken.

- An IUD has come out of place.

\section{Proceed with care in the following situations}

\section{CONDITION}

Women with history of severe cardiovascular complications (e.g.,

IHD, CVA or other thromboembolic conditions)

Woman with angina pectoris

Women suffering from migraine

Women with severe liver disease

(including jaundice)

\section{SUGGESTED ACTION}

Should be given the regimen without the delay; they may need follow-up after they have taken the pills.

Any delay may take them to the point beyond 120 hours when ECPs are not effective anymore,

Pregnancy poses much more risk for these women than ECPs do.

The duration of use of EC is less than that of regular use of COCs or POPs and thus would be expected to have less clinical impact.

\section{WHO SHOULD NOT USE}

$E C$ is not to be used as a regular method. Recurrent demand for $E C$ is an indication that the woman requires further counseling on other contraceptive options.

Frequently repeated EC use may be harmful for women with conditions classified as "Use with care" (category 2) and "Who should not use" (categories 3 and 4) for hormonal methods.

EC should not be given to women who are known to be pregnant.

The success of emergency contraception depends on awareness and knowledge of its availability/efficacy prior to an unprotected, unplanned act. The method is only effective if potential users are aware of the method by prior information and counseling.

\section{KEY POINTS FOR PROVIDERS AND CLIENTS}

- EC pills should be started as soon as possible, but within 120 hours of unprotected sex

- EC is referred to as the "morning-after pill," but this reference is misleading as it implies that one has to wait for sometime before using the pill.

- Emergency contraception pills do not work once a woman is pregnant. Therefore women/girls who are already pregnant should not take emergency contraception pills. 


\section{Management of common side effects}

\begin{tabular}{|l|l|}
\hline \multicolumn{1}{|l|}{ SIDE EFFECTS } \\
$\begin{array}{l}\text { Nausea and vomiting } \\
\text { (more common with } \\
\text { COC regimen) }\end{array}$ & $\begin{array}{l}\text { Women should be counseled of the possible occurrence of nausea at the } \\
\text { time of ECP supply. For women using a combined pill or POP for ECP, where } \\
\text { possible, an anti-emetic may be used before the pills are taken. } \\
\text { If vomiting occurs within 2 hours, repeat the previous ECP dose orally as } \\
\text { soon as possible. } \\
\text { If a woman again vomits, give the dose vaginally (place the needed dose } \\
\text { high up in the vagina) }\end{array}$ \\
\hline Slight irregular bleeding & $\begin{array}{l}\text { Reassure that this is not a sign of pregnancy or other condition. } \\
\text { Irregular bleeding due to ECPs is common and will stop without treatment. }\end{array}$ \\
\hline $\begin{array}{l}\text { Change in timing of next } \\
\text { monthly bleeding }\end{array}$ & $\begin{array}{l}\text { Explain that it is not unusual for the next monthly bleeding to start a few days } \\
\text { earlier or later than expected. } \\
\text { Assess for pregnancy if woman's next monthly bleeding is more than one } \\
\text { week later than expected. }\end{array}$ \\
\hline
\end{tabular}

\section{WHO CAN PROVIDE EC?}

\section{Clinical Providers}

- Medical Doctors

- Nurses/Midwives

- Clinical officers

\section{Non-clinical providers}

- Trained Pharmacists/Pharmaceutical Technologists

- Trained Community Health Extension Workers (CHEWs)- Nurse/midwives, Public Health Officers (PHO), Public Health Technicians (PHT)

- Trained Community Health Workers (CHWs) including Community-based Distributors (CBDs)

\section{Other Providers}

- All trained providers including CBDs, pharmacy assistants, community health workers, trained peer counselors. ${ }^{1}$

\section{WHERE EC CAN BE PROVIDED}

All service delivery points:

- Level 4 and above (hospitals)

- Level 3 (health Centers, nursing/maternity homes)

- Level 2 (dispensaries, HTC centers, private clinics)

- Level 1 (outreach, including CHWs, CBDs, and mobile services), pharmacies/ chemists, SGBV centers) and any site with a trained provider (home, shop).

1 World Health Organisation (2012), WHO recommendations. Optimizing health worker roles to improve access to key maternal and newborn health interventions through task shifting. 
STARTING FAMILY PLANNING METHODS AFTER EC

\begin{tabular}{|l|l|}
\hline METHOD & WHEN TO START \\
\hline Condom & Immediately after EC use also for dual protection \\
\hline Oral contraceptive pills & Next day after $2^{\text {nd }}$ dose of EC or 1-7 days after menses \\
\hline Injection & \\
\cline { 1 - 1 } IUD & \\
\cline { 1 - 1 } Norplant & \\
\cline { 1 - 1 } Permanent method & \\
\cline { 1 - 1 } Natural method &
\end{tabular}

\section{BRIDGING EC USERS TO OTHER REPRODUCTIVE HEALTH SERVICES}

EC providers are expected to explain the mode of action of EC to the client including the fact that EC is not $100 \%$ effective at reducing the risk of pregnancy. Except in the case of rape, providers are expected to discuss the use of a regular FP method and emphasize that EC pills are for emergency use only. All providers are supposed to inform users of all FP methods available and that the FP methods (except condoms) do not protect women against sexually transmitted infections (STIs) including HIVIAIDS. Many women who need EC also need protection from STIs/HIV and therefore counseling on EC is an opportunity to discuss the risks and prevention options for STIs/HIV/AIDS including the need for counseling and testing services. Refer clients for FP and other RH services. Women who have been raped or traumatized also need to be referred for more comprehensive medical and psychosocial care.

\section{Common Questions}

- What are the effects of EC on periods? EC pills do not cause periods to start immediately. They will come at the normal time but may delay or come early by $2-3$ days

- Can EC pills protect one for the rest of the cycle? They will not, and any further unprotected acts put one at risk. Women should use a regular method of FP or condoms for further protection.

- When can I resume/start a regular FP method after taking EC? One can start by using condoms and pills. One has to wait until next period to begin using injections, IUDs, and implants.

- Can I use EC pills every time I have sex? Women/girls should not use EC pills as a regular method. They should only be used in emergency situations. EC pills are less effective than many regular FP methods

- What if I had sex multiple times before taking EC pills? You can still use EC pills if the last time you had sex was within 5 days. If one is already pregnant from an earlier act of unprotected sex, the EC pills will not have any effect. 


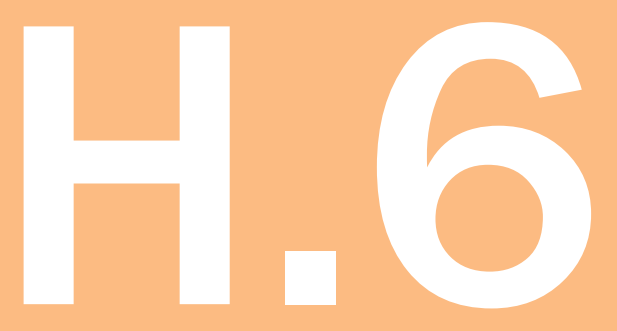

\section{WHO}

FACT SHEET

ON EMERGENCY

CONTRACEPTION 


\section{Emergency contraception}

Fact sheet $\mathrm{N}^{\circ} 244$

July 2012

\section{Key facts}

- Emergency contraception can prevent most pregnancies when taken after intercourse.

- Emergency contraception can be used following unprotected intercourse, contraceptive failure, incorrect use of contraceptives, or in cases of sexual assault.

- There are two methods of emergency contraception: emergency contraceptive pills (ECPs) and copperbearing intrauterine devices (IUDs).

- When inserted within five days of unprotected intercourse, a copper-bearing IUD is the most effective form of emergency contraception available.

- The emergency contraceptive pill regimen recommended by WHO is one dose of levonorgestrel $1.5 \mathrm{mg}$, taken within five days (120 hours) of unprotected intercourse.

Emergency contraception, or post-coital contraception, refers to methods of contraception that can be used to prevent pregnancy in the first few days after intercourse. It is intended for emergency use following unprotected intercourse, contraceptive failure or misuse (such as forgotten pills or torn condoms), rape or coerced sex.

Emergency contraception is effective only in the first few days following intercourse before the ovum is released from the ovary and before the sperm fertilizes the ovum. Emergency contraceptive pills cannot interrupt an established pregnancy or harm a developing embryo.

\section{Who needs emergency contraception?}

Any woman of reproductive age may need emergency contraception at some point to avoid an unwanted pregnancy.

\section{In what situations should emergency contraception be used?}

Emergency contraception can be used in a number of situations following sexual intercourse:

- When no contraceptive has been used.

- When there is a contraceptive failure or incorrect use, including:

- condom breakage, slippage, or incorrect use;

- three or more consecutively missed combined oral contraceptive pills;

- the progestogen-only pill (minipill) taken more than three hours late (or more than 12 hours late if taking a $0.75 \mathrm{mg}$ desogestrel-containing pill);

- norethisterone enanthate (NET-EN) progestogen-only injection taken more than two weeks late;

- depot-medroxyprogesterone acetate (DMPA) progestogen-only injection taken more than four weeks late;

- the combined estrogen-plus-progestogen monthly injection taken more than seven days late;

- dislodgment, delay in placing, or early removal of a contraceptive hormonal ring or skin patch;

- dislodgment, breakage, tearing, or early removal of a diaphragm or cervical cap;

- failed withdrawal (e.g., ejaculation in the vagina or on external genitalia);

- failure of a spermicide tablet or film to melt before intercourse;

- miscalculation of the periodic abstinence method, or failure to abstain or use a barrier method on the fertile days of the cycle;

- expulsion of an intrauterine contraceptive device (IUD) or hormonal contraceptive implant.

- In cases of sexual assault when the woman was not protected by an effective contraceptive method. 


\section{Methods of emergency contraception}

There are two methods of emergency contraception:

1. emergency contraception pills (ECPs)

2. copper-bearing intrauterine devices (IUDs).

\section{Emergency contraception pills}

WHO recommends levonorgestrel for emergency contraceptive pill use. Ideally, this progestogen-only method should be taken as a single dose $(1.5 \mathrm{mg})$ within five days (120 hours) of unprotected intercourse. Alternatively, a woman can take the levonorgestrel in two doses ( $0.75 \mathrm{mg}$ each; 12 hours apart).

\section{Mode of action}

Levonorgestrel emergency contraceptive pills prevent pregnancy by preventing or delaying ovulation. They may also work to prevent fertilization of an egg by affecting the cervical mucus or the ability of sperm to bind to the egg.

Levonorgestrel emergency contraceptive pills are not effective once the process of implantation has begun, and they will not cause abortion.

\section{Effectiveness}

Based on reports from nine studies including 10,500 women, the WHO-recommended levonorgestrel regimen is $52-94 \%$ effective in preventing pregnancy. The regimen is more effective the sooner after intercourse it is taken.

\section{Safety}

Levonorgestrel-alone emergency contraception pills are very safe and do not cause abortion or harm future fertility. Side effects are uncommon and generally mild.

\section{Medical eligibility criteria and contraindications}

Emergency contraceptive pills prevent pregnancy. They should not be given to a woman who already has a confirmed pregnancy. However, if a woman inadvertently takes the pills after she becomes pregnant, the available evidence suggests that the pills will not harm either the mother or her fetus.

Emergency contraceptive pills are for emergency use only and are not appropriate for regular use as an ongoing contraceptive method because of the higher possibility of failure compared with non-emergency contraceptives. In addition, frequent use of emergency contraception can result in side effects such as menstrual irregularities, although their repeated use poses no known health risks.

There are no medical contraindications to the use of levonorgestrel emergency contraception pills.

\section{Copper-bearing intrauterine devices (IUDs)}

WHO recommends that a copper-bearing IUD, as an emergency contraceptive, be inserted within five days of unprotected intercourse. This may be an ideal emergency contraceptive for a woman who is hoping for an ongoing, highly effective contraceptive method.

\section{Mode of action}

As emergency contraception, the copper-bearing IUD primarily prevents fertilization by causing a chemical change that damages sperm and egg before they can meet.

\section{Effectiveness}

When inserted within five days of unprotected intercourse, a copper-bearing IUD is over $99 \%$ effective in preventing pregnancy. This is the most effective form of emergency contraception available. Once inserted, the woman can continue to use the IUD as an ongoing method of contraception, and she may choose to change to another contraceptive method in the future. 


\section{Safety}

A copper-bearing IUD is a very safe form of emergency contraception. The risks of infection, expulsion or perforation are low.

\section{Medical eligibility criteria and contraindications}

The only situation in which a copper-bearing IUD should never be used as emergency contraception is if a woman is already pregnant. There are other contraindications to using a copper-bearing IUD as ongoing contraception, which also should be considered before its use as emergency contraception. For more information, please refer to the WHO Medical Eligibility Criteria for Contraceptive Use.

\section{WHO response}

WHO's activities on emergency contraception form part of its work to provide access to high-quality services for family planning, particularly for the most vulnerable populations. This work is shaped by the WHO Global Reproductive Health Strategy.

In addition, through the UNDP/UNFPA/WHO/World Bank Special Program of Research, Development and Research Training in Human Reproduction (HRP), research is carried out that aims to provide the widest range of safe and effective family planning methods, as well as clinical research into novel methods or uses.

WHO reaffirms its commitment to keeping emerging evidence under close review through its Continuous Identification of Research Evidence (CIRE) system.

\section{For more information contact:}

WHO Media centre

Telephone: +4122 7912222

E-mail: mediainquiries@who.int 


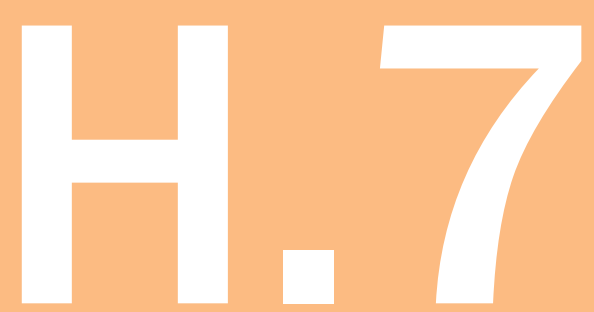

MOH MONTHLY

SUPERVISION

AND

MONITORING

TOOL 
(For use by provincial/regional, district/county/local authorities and officers in charge of health facilities.)

\section{Objectives of Supervision and Monitoring Visits:}

- To increase the knowledge and strengthen the skills of health providers to effectively manage the logistics system for FP including EC .

- To identify performance weaknesses, and improve performance through on job training as needed.

- To ensure that established logistics guidelines and procedures regarding FP/EC commodities are being followed.

- To estimate the required quantities of FP commodities including EC per . that are ordered or issued

- To assess whether clients are getting the services they want when they need them

- To verify that all records are correctly maintained and reports are submitted on time.

- To determine the quantity of supplies to order or issue

- To discuss the way forward with the local health management teams with a view to increasing access to FP/ECPs in the community and clients seeking these services

\section{Health Facility Characteristics}

a) Name of facility and postal address.

b) Type of Facility (Circle appropriate code: Hospital = 1; Health center = 2; Dispensary = 3;)

c) Managing authority (Circle appropriate code: Government=1; Faith-based = 2; $\mathrm{NGO}=3$; Private $=4$; Other $=5$ )

d) District/County/Local authority

e) Province/Region

f) Date of visit

g) Person interviewed

\section{Personnel Characteristics}

Indicate the number of staff working at the facility who are trained in FP including EC

\begin{tabular}{|l|l|l|l|}
\hline \multicolumn{2}{|l|}{} & \multicolumn{2}{l|}{$\begin{array}{l}\text { No. of staff working in the facility trained in FP including EC in the } \\
\text { past 1-3 years (in service) }\end{array}$} \\
\hline Cadre & $\begin{array}{l}\text { Total no. in } \\
\text { the facility }\end{array}$ & $\begin{array}{l}\text { No. trained in FP \& } \\
\text { EC (in service) }\end{array}$ & $\begin{array}{l}\text { No. trained in other RH services e.g., STIs/ } \\
\text { HIV, gender issues, safe motherhood, etc. }\end{array}$ \\
\hline Medical officers & & & \\
\hline Clinical officers & & & \\
\hline Nurses & & & \\
\hline Pharmacy staff & & & \\
\hline Others (specify) & & & \\
\hline
\end{tabular}




\section{FP/EC Staff Training}

a) Are there regular continuing medical education /OJT programs in the district(s)/facilities on $\mathrm{FP} / \mathrm{EC}$ activities?

b) How do you ensure that as many staff as possible in the district(s)/facilities have access to these updates?

\section{Availability of FP/EC Tools in the Facility}

Are the following tools available and in use in the facility?

\begin{tabular}{|l|l|l|l|}
\hline Tools available & $\begin{array}{l}\text { Yes in use } \\
\text { Place tick } \sqrt{ }\end{array}$ & $\begin{array}{l}\text { Not in use } \\
\text { Place tick } \sqrt{ }\end{array}$ & $\begin{array}{l}\text { Explanation if tool (s) } \\
\text { not in use }\end{array}$ \\
\hline FP register with EC column & & & \\
\hline $\begin{array}{l}\text { District monthly contraceptives request and } \\
\text { reporting form }\end{array}$ & & & \\
\hline $\begin{array}{l}\text { Facility monthly contraceptives request and } \\
\text { reporting form }\end{array}$ & & & \\
\hline Job aids (F/EC) & & & \\
\hline Other (specify) & & & \\
\hline
\end{tabular}

\section{Are the Following Materials Present in the Health Care Provider's Room?}

\begin{tabular}{|l|l|l|l|}
\hline Materials available & $\begin{array}{l}\text { Yes in use } \\
\text { Place tick } \sqrt{ }\end{array}$ & $\begin{array}{l}\text { Not in use } \\
\text { Place tick } \sqrt{ }\end{array}$ & Explanation if tool(s) not in use \\
\hline National FP Guidelines & & & \\
\hline Post-rape/SGBV guidelines & & & \\
\hline FP job aids inclusive of EC ones & & & \\
\hline EC counseling job aid & & & \\
\hline Others (specify) & & & \\
\hline
\end{tabular}

\section{Status of Commodities During the Month}

Did the facility experience stock outs of the following commodities for more than 7 days last month? (Place a tick in the appropriate "yes" or "no" column for each of the items listed). If FP commodities were not available, discuss with the facility staff and outline the reasons in the appropriate row in the table.

\begin{tabular}{|l|l|l|l|l|}
\hline \multicolumn{2}{|l|}{ Commodity stock outs for more than 7 days } & Y & N & Reasons for stock outs (if response was “Y”) \\
\hline a) & Combined oral pill (COP) & & & \\
\hline b) & Emergency contraceptive pills & & & \\
\hline c) & IUD & & & \\
\hline d) & Depo Provera & & & \\
\hline e) & $\begin{array}{l}\text { Implants (e.g., Jadelle, Implanon, } \\
\text { Sino-implant) }\end{array}$ & & & \\
\hline f) & Male condoms & & & \\
\hline g) & Female condoms & & & \\
\hline h) & Microlut & & & \\
\hline i) & Others (specify) & & & \\
\hline
\end{tabular}




\section{ECP Provision to Clients}

i) Which cadres of health care providers prescribe ECPs to the clients?

ii) In which areas of the facility can EC services be accessed by the clients?

iii) Are the EC services and commodities accessible at night and in the weekends?

iv) What EC regimes are used?

- Dedicated pill

- "Yuzpe" regimen

v) Find out from the district/health facility the most common indication (s) for ECPs in their respective areas/region(s):

- Rape

- FP method failure

- Just had unprotected sex

- Others (specify

\section{Service Statistics}

Check for the number of clients who received FP and EC services from the facility/district or county in the last completed quarter.

\section{Comments/remarks}

a) Outline some of the achievements, program strengths and available opportunities for strengthening integration activities for RTIs/STIs/HIV within reproductive health settings in the facility, etc.

b) Outline some of the key challenges, and constraints experienced during the month.

\section{Supervision and Monitoring Team During this Visit Comprised the Following Officials:}
a) Name
Designation
Dept/Division/Unit.
b) Name
Designation
Dept/Division/Unit.
c) Name
Designation
Dept/Division/Unit.
d) Name
Designation
Dept/Division/Unit.
e) Name
Designation
Dept/Division/Unit.

\section{Supervision and Monitoring Report was prepared by:}

Name

Designation

Dept/Division/Unit. 


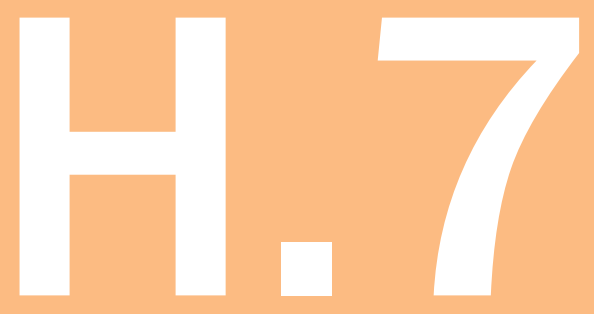

KEY M\&E

INDICATORS

FOR FP

COMMODITIES/

EC PILLS 
This table lists the indicators for FP commodities/EC pills (adapted from Reproductive Health, Supplies Coalition, Monitoring and Evaluation Framework (2007-2015). The indicators are listed under each objective, broad goal and strategic area.

\section{INDICATOR}

METHOD OF COLLECTIONNERIFICATION

Goal 1: Increase predictability and sustainability of financing for FP/EC supplies

Objective 1: Mobilize additional new resources

i) National budgetary line item for FP commodities including EC pills

Government reports; $\mathrm{MOH}$ or MOF verification of budget line item

ii) Increase in donor funding for FP commodities includ- Validated, procured, and paid for reproductive health suping EC pills in the past $1-3$ years

plies from government records in the past $1-3$ years

\section{Objective 2. Access existing resources in support of FP/EC Supplies}

- Proportion of the country's health budget for FP com- Government reports; MOH or MOF verification of budget modities including EC pills actually spent in the last 3 line item for $\mathrm{RH}$ supplies in the past 1-3 years years

Objective 3. Mobilize total market resources for FP/EC supplies

a) Examples of initiatives in the country for expanding $\quad$ Market segmentation studies; PPPs; reports from partners the total market for FP commodities including EC pills such as PSI, among others

b) Increase in the non-public sector share of the market Market surveys undertaken by social marketing partners on for condoms, pills including EC pills

sales and others

Goal 2. Strengthen the capacity of health systems to sustain FP/EC supplies

Objective 1. Strengthen existing systems

i) A functional FP commodity committee or similar $\quad$ Program reports on existence and performance of commechanisms for managing $\mathrm{RH} / \mathrm{FP}$ supplies in place

ii) Levonorgestrel or equivalent products listed on the national essential drug list

iii) Monitor the supply chain for ECPs in the public sector at all levels periodically

modity security committees or taskforces

Verify from the national essential drugs list

$\mathrm{MOH}$ program eports and those from key partners assisting governments with supply chain performance

\section{Objective 2. To avert RH supply disruptions at national level}

- Availability and use of guidelines/ procedures for $\quad$ Minutes of the meetings/decisions taken and carried averting EC stock shortage through

Objective 3. Develop systems for emergency situations

a) Number of doses or units of dedicated ECPs issued to Database at central warehouses in the public sector. clients or distributed* in the last one complete year in Records of main EC brand distributors. Additional records both the public and private sector

b) Initiatives to integrate provision of FP/EC Pills into humanitarian relief efforts could be obtained from other humanitarian agencies

Goal 3: Steer EC mainstreaming activities within the broader RH services

Objective 1. Foster greater harmonization among stakeholders at country level

\begin{tabular}{l|l} 
- Examples of coordinated action by partners in a & Narratives of instances from working groups, partners and
\end{tabular} country, with the aim of strengthening the security of FP commodities/EC pills

Objective 2. Promote new knowledge

i) Examples of all new tools, publications, and research $\quad$ Routine collection of reports and initiatives by $\mathrm{MOH}$ and initiatives produced in the past $1-3$ years on EC mainstreaming work.

ii) Annual increase in visits to the country's RH/FP (or $\quad$ Website hit figures on FP commodities/EC pills and EC equivalent) website country-led teams from partners

mainstreaming activities produced by Active Elements (website host)

\section{Objective 3. Establish support systems}

a) Availability of an M\&E report on performance of FP $\quad$ Analysis and evaluation of results of indicator changes services including EC activities against baseline values in both public and private sectors

b) Identify sustainable ways of mainstreaming EC activities into the broader $\mathrm{RH}$ activities

Minutes of the meetings

Routine collection of reports

Records of supplies at services such as SGBV centers

*In functional partnerships, it is feasible to obtain this information from records of the main EC brand distributors. 

